\title{
THERMAL PERFORMANCE OF THE RESIDENTIAL OPEN SPACE IN SANA'A CITY - YEMEN (SUMMER PERIOD)
}

\author{
(Received Journey 18, 2011 Accepted March 22, 2011)
}

More attention is being paid to the provision of thermal comfort in the environments in which people live. To achieve this, the need arises to study the impact of climate on design of urban and architectural spaces. Urban development projects provide a good opportunity for the designer to take into account the elements of climate in order to achieve human comfort and to enhance the climatic performance of these spaces.

The aim of this paper is to study the thermal performance of urban spaces, especially the residential ones, in summer period. This happens through making field measurements for air temperature, relative humidity and air speed in chosen residential urban spaces in two parts of Sana'a: the old and the new to identify the features of the generated microclimate and to analyze its patterns and characteristics, and to know the best performance for the residential urban spaces. It is hoped that the concluded recommendations will help when designing the residential urban spaces in Sana'a city.

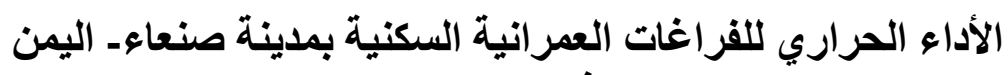

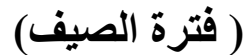

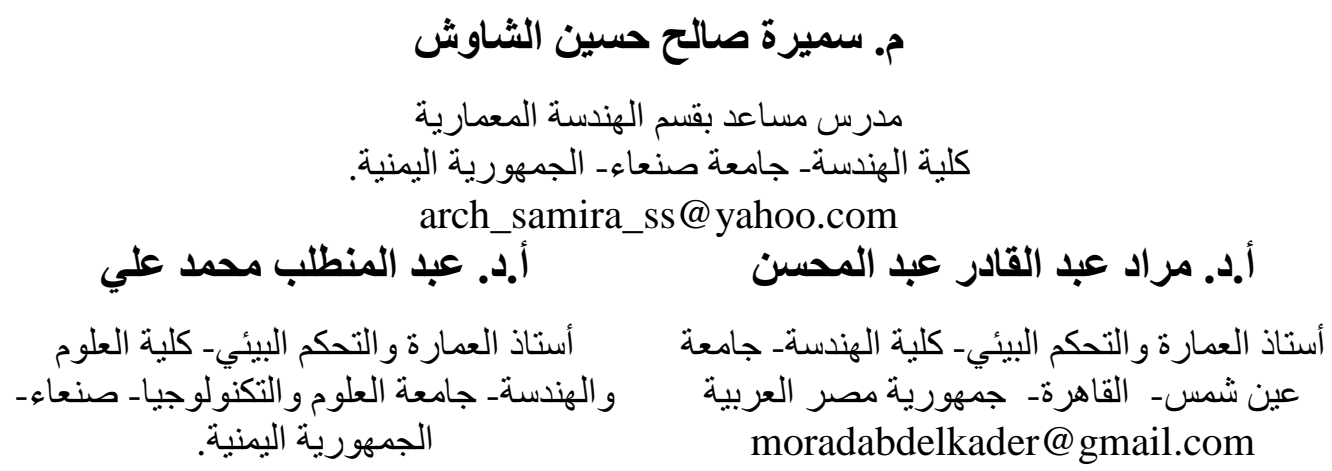

a.monteleb@yahoo.com.

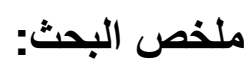

مع التزايد المطرد للسكان في مدن العالم، ز اد الاهتمام بتوفير الراحة الحرارية في البيئات التي يعيش فيها هؤ لاء

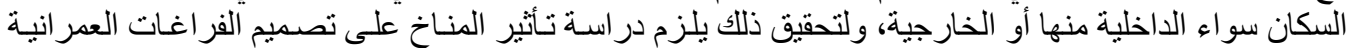

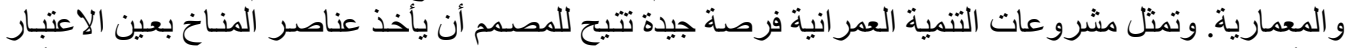

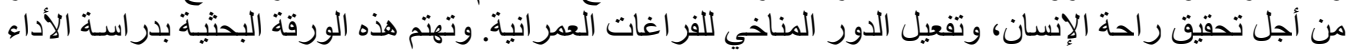

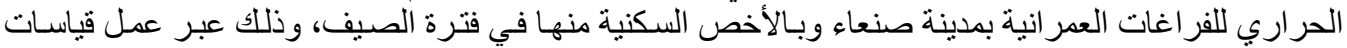

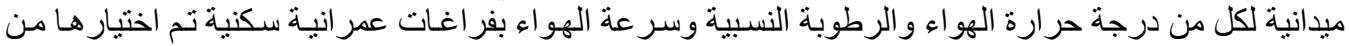

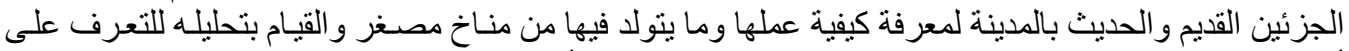

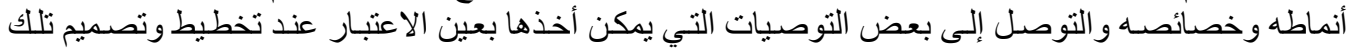


مقدمة:

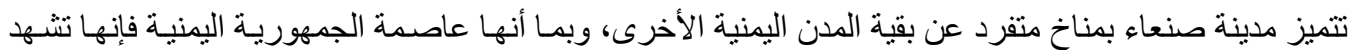

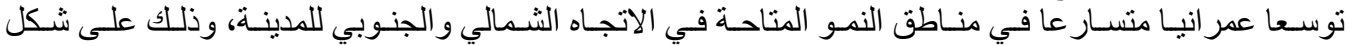

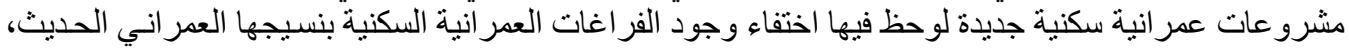

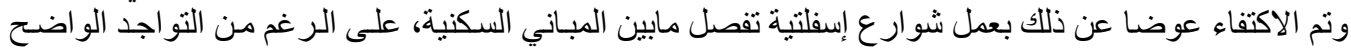

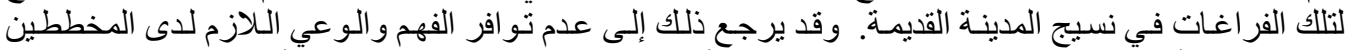

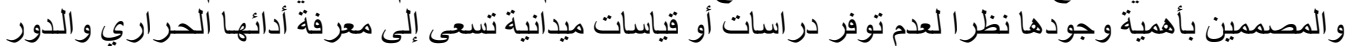

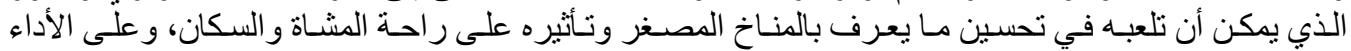

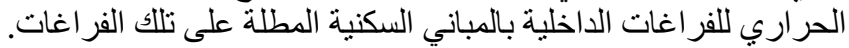

\section{1. الوصف الجغزافي والمناخي للمدينة}

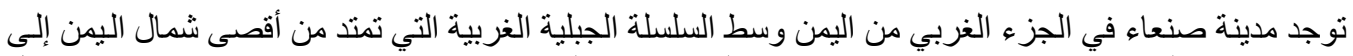

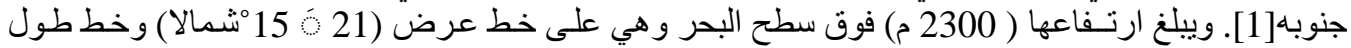

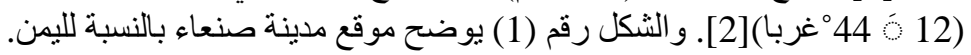

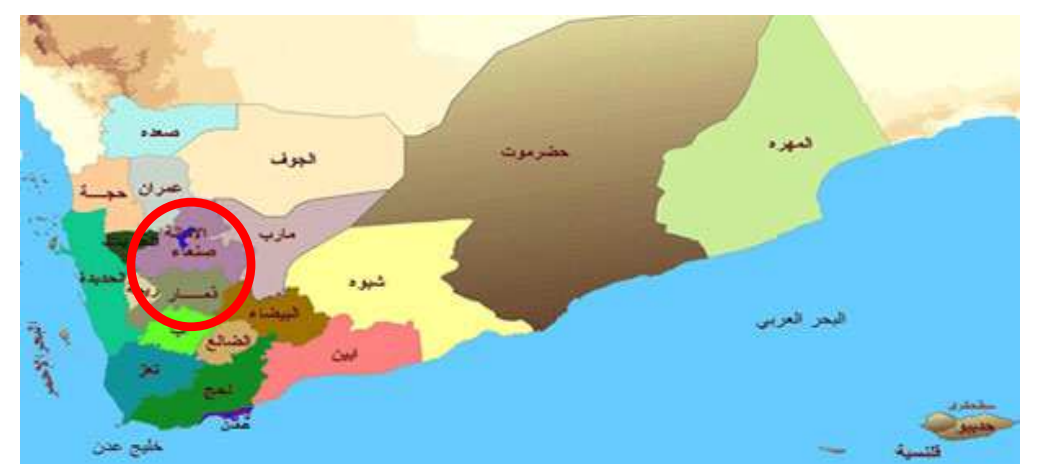

شكل (1): تقسيمات المدن اليمنية وموقع مدينة صنعاء]2].

تحيط الأرض المرتفعة بصنعاء من جميع النواحي، لتصبح أقرب إلى أن تكون منطقة حوضية. ويحتل موقع مدينة

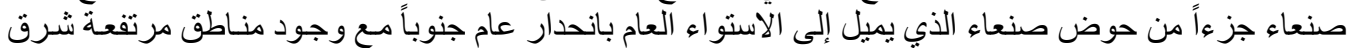

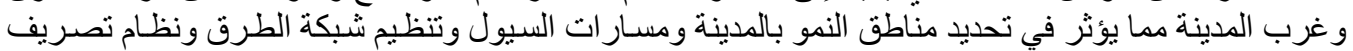

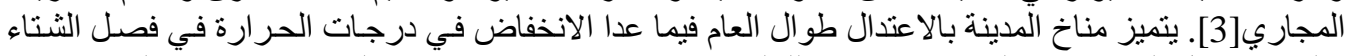

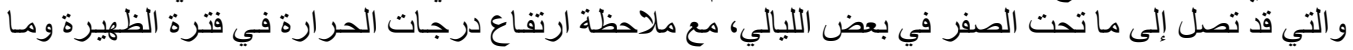

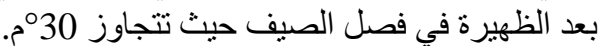

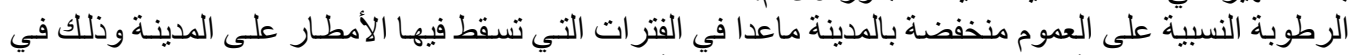

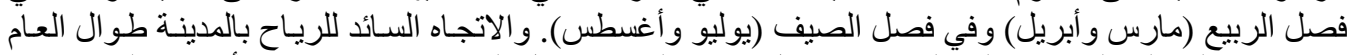

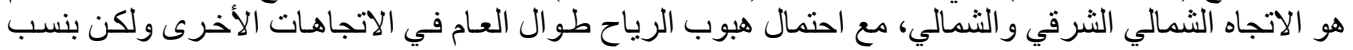

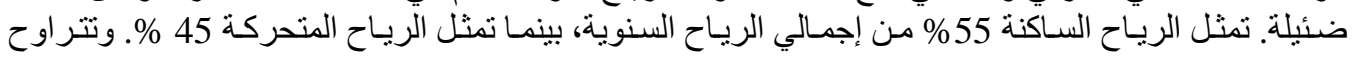

[1] http://www.marefa.org/index.php 2010/5/28

${ }^{32}$ http://www.google Earth 2010/10/12

[1] http://travel.m3com.com.sa 2010/5/28

[2] محمد عبد الله اللساني:" المناخ و الموارد المائية في حوض صنعاء"، رسالة ماجستير، قشم الجغر افيا، كلية الآداب، جامعة صنعاء، 2002م. 


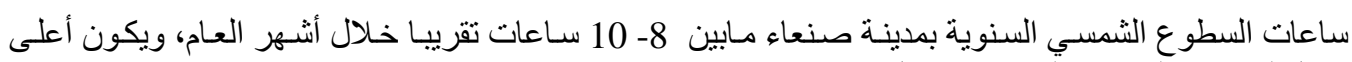

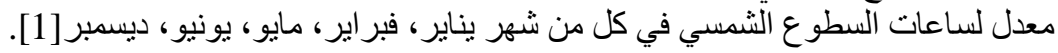

\section{2. مناطق الاراسة}

تم اختيار مدينة صنعاء للار اسة لاحتو ائها على جزئين مختلفين تمامـا من حيث النسيج و التئكوين العمر اني وهمـا:

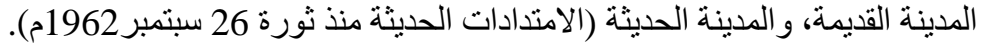

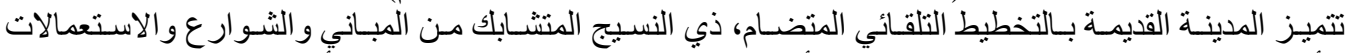

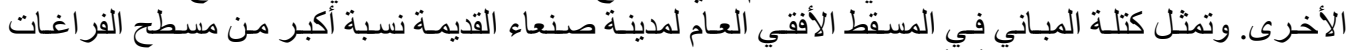

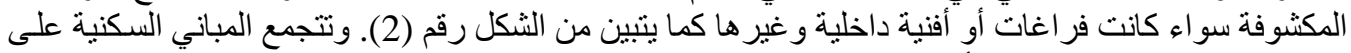

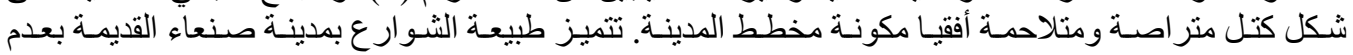

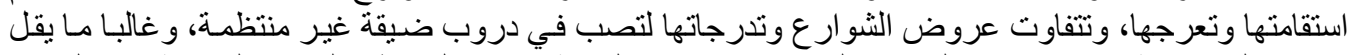

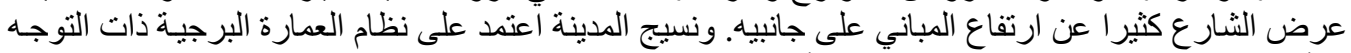

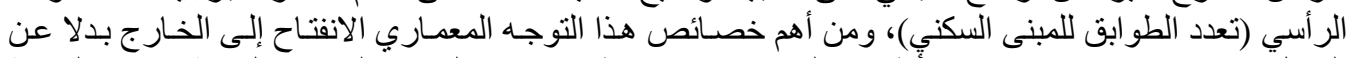

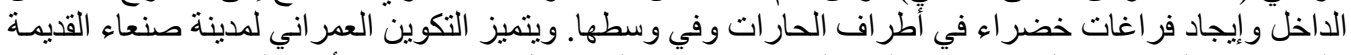

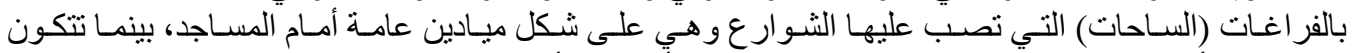
الفر اغات الأصغر بين المجمو عات السكنية والتي تعددت أُنكالها و أنواعها.

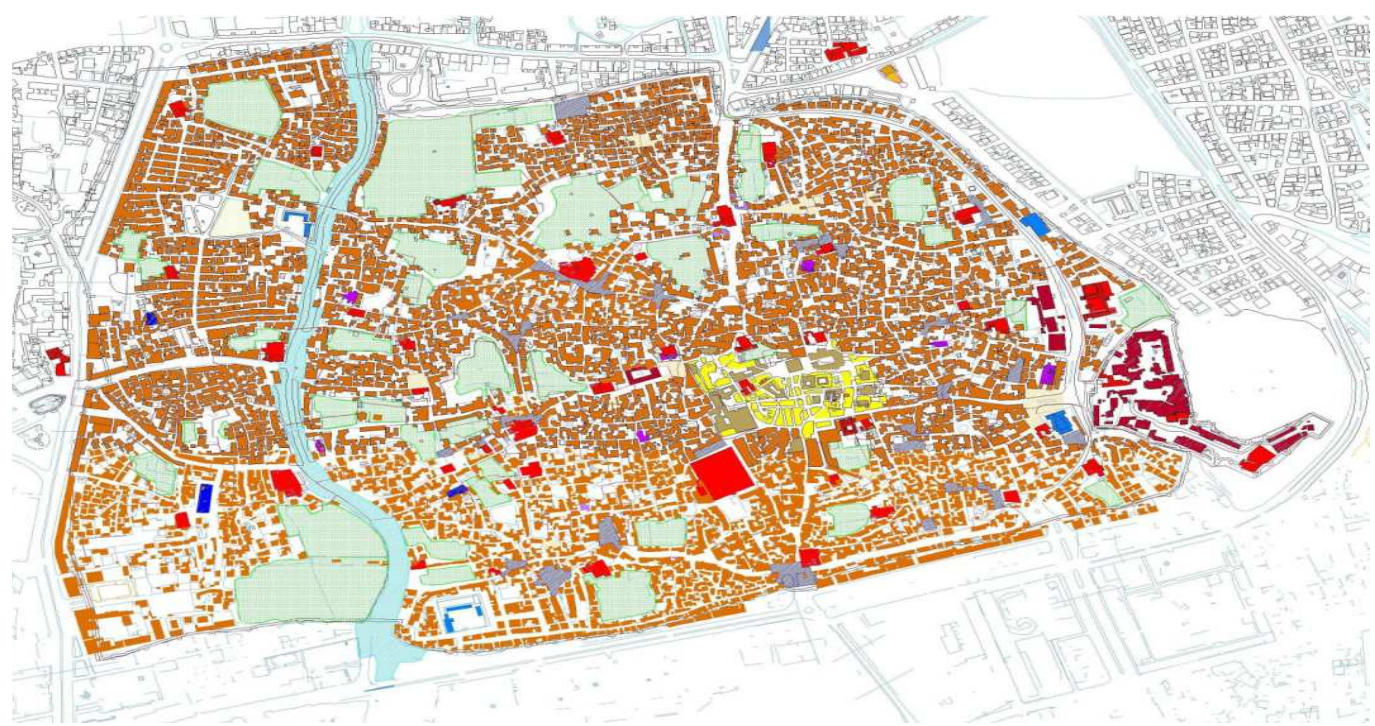

شكل (2): مخطط عام لمدينة صنعاء القديمة[2]

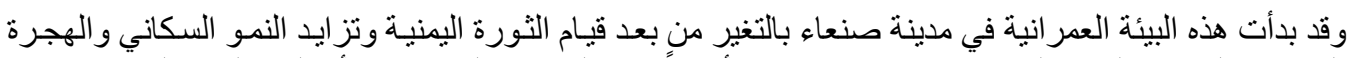

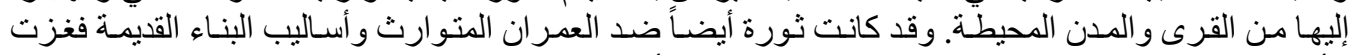

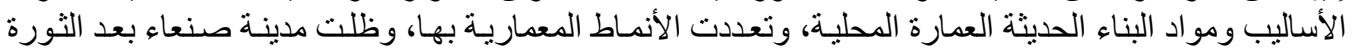

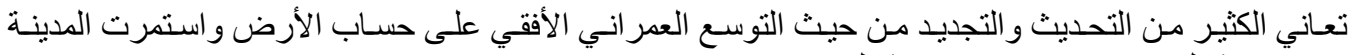

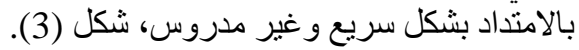

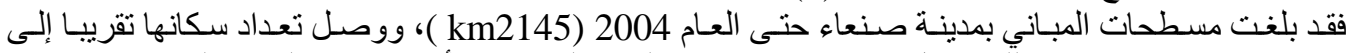
(1,747,627 شخص)، وذلك بمعدل (83 1 / شخص) لنفس العام[1]]. و أصبح نسيج المدينة الحديثة ذا خطوط

[3] سميرة صـالح الثـاوش:" تأثير الظروف المناخية على عمـارة المباني السكنية بمدينة صنعاء ـ اليمن"، قسم العمـارة،

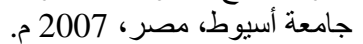
[1] [ مركز الدراسات و التدريب المعماري، الهيئة العامة للمحافظة على المدن التاريخية، صنعاء، اليمن، تحديث 2008. 
هندسية منتظمة على عكس التلقائية الموجودة في نسيج المدينة القديمـة، وظهرت الماتِ المباني السكنية و المباني العامـة

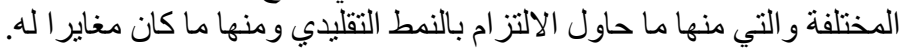

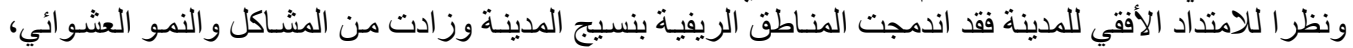

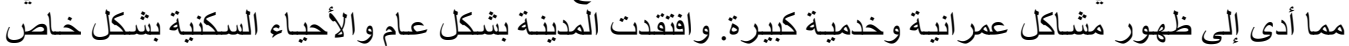

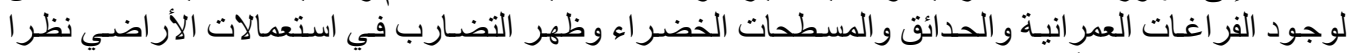

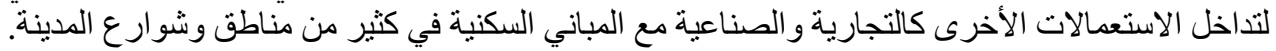

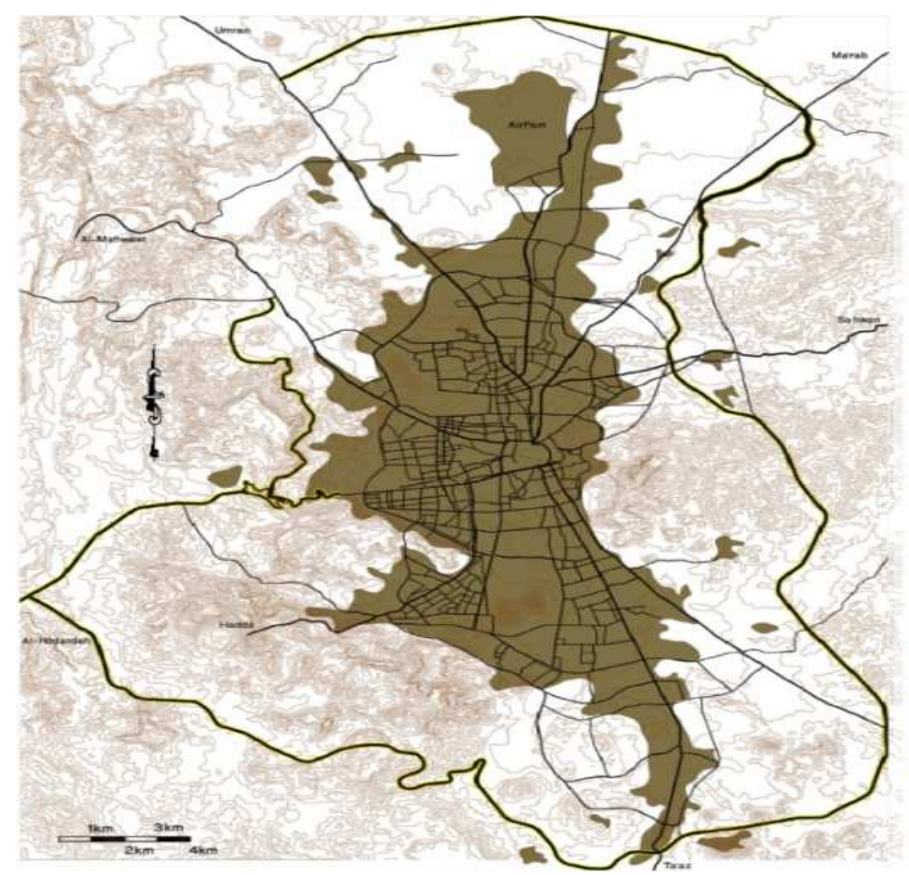

شكل (3): مخطط عام يوضح امتداد مدينة صنعاء [2].

وظهرت الأنماط الحديثة من المباني ذات الثكل المكعب مسقطها الأفقي إما مربع أو مستطيل، ولا تز ال المباني

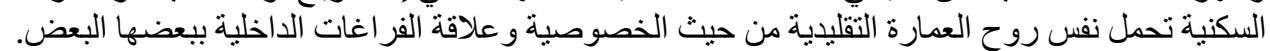

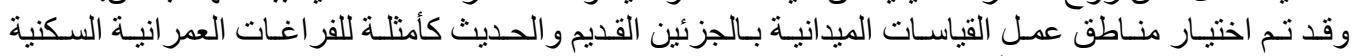
الموجودة للتعرف على كيفية أدائها حر اريا. وفيما يلي وصف للفي للفر اغات المختارة لعمل القياسات:

\section{1 1المداينة القديمة (حارة الجلاء):}

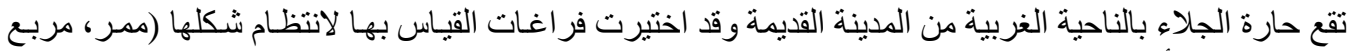

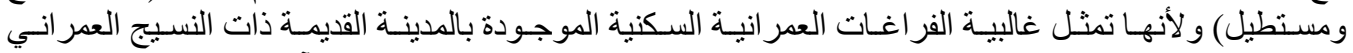

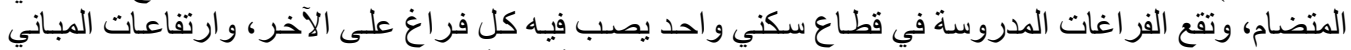

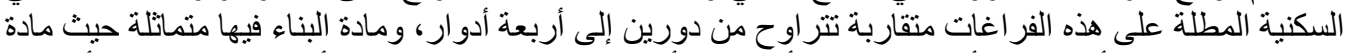

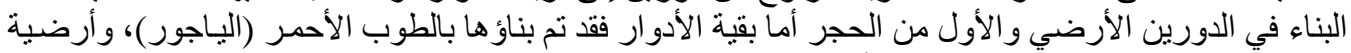

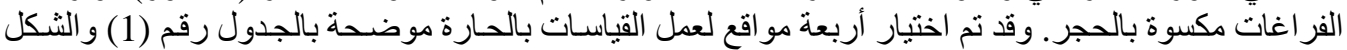

رقم (4).

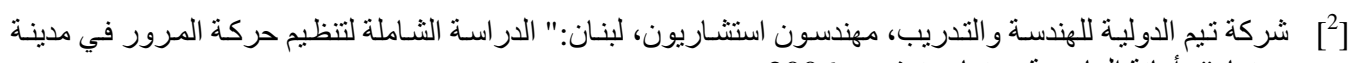

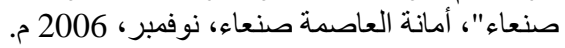
[1] [ مركز الدر اسات و التدريب المعماري، الهيئة العامة للمحافظة على المدن التاريخية، صنعاء، اليمن، تحديث 2008. 
2. 2 2

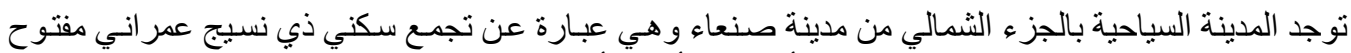

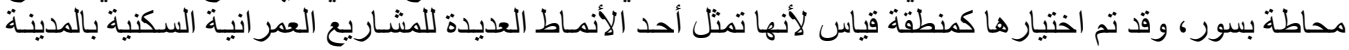

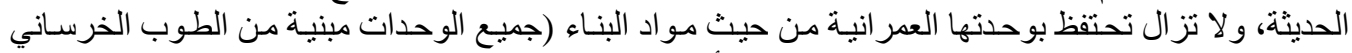

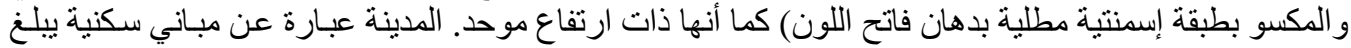

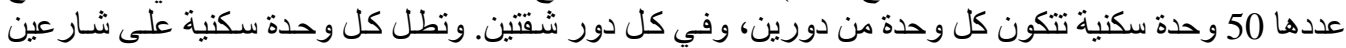

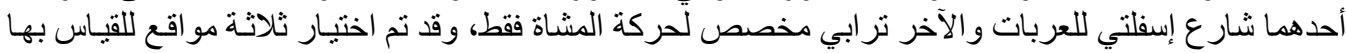

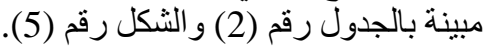

جدول (1): تفاصيل مواقع القياسات بالمدينة القديمة"].

\begin{tabular}{|c|c|c|c|c|c|c|}
\hline \multicolumn{3}{|c|}{ النسبة المئوية لعناصر الموقع \% } & \multirow{2}{*}{ المتوسطاع المباع م } & \multirow{2}{*}{ الارتفاع/ العرضة } & \multirow[b]{2}{*}{ توجيه الموقع } & \multirow[b]{2}{*}{ الموقع } \\
\hline خضر منطقة & أرضيات & 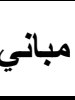 & & & & \\
\hline 0 & 25 & 75 & 10 & 1.35 & شمالي جنوبي & 1 \\
\hline 0 & 18 & 82 & 11 & 6.3 & شمالي جنوبي & 2 \\
\hline 0 & 17 & 83 & 11 & 3.5 & شمالي جنوبي & 3 \\
\hline 0 & 33 & 67 & 8 & 1.6 & شرقي غربي & 4 \\
\hline
\end{tabular}

جدول (2): تفاصيل مواقع القياسات بالمدينة الحديثة] [*].

\begin{tabular}{|c|c|c|c|c|c|c|}
\hline \multicolumn{3}{|c|}{ النسبة المئوية لعناصر الموقع \% } & \multirow{2}{*}{ المتبطاع المباع م } & \multirow{2}{*}{ الارتفاع/ العرضة } & \multirow[b]{2}{*}{ توجيه الموقع } & \multirow[b]{2}{*}{ الموقع } \\
\hline خضر منطقة & أرضيات & 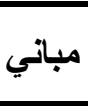 & & & & \\
\hline 13 & 64 & 23 & 8 & 2.5 & شمالي جنوبي & 1 \\
\hline 21 & 54 & 25 & 8 & 1.1 & شرقي غربي & 2 \\
\hline 26 & 51 & 23 & 8 & 1.2 & شمالي جنوبي & 3 \\
\hline
\end{tabular}

\section{3. الأجهزة المستخدمة للقياس}

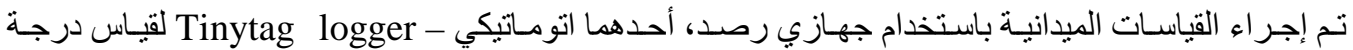

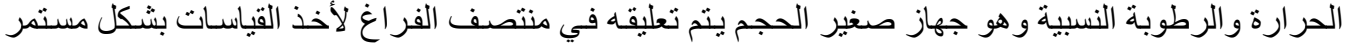

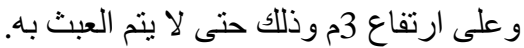

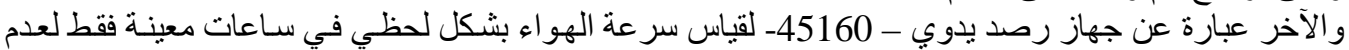

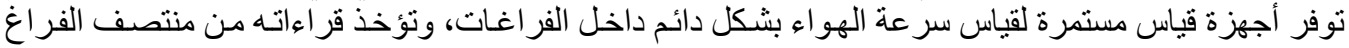

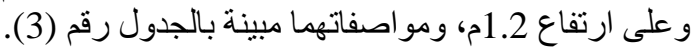


جدول (3): الأجهزة المستخدمة للقياس.

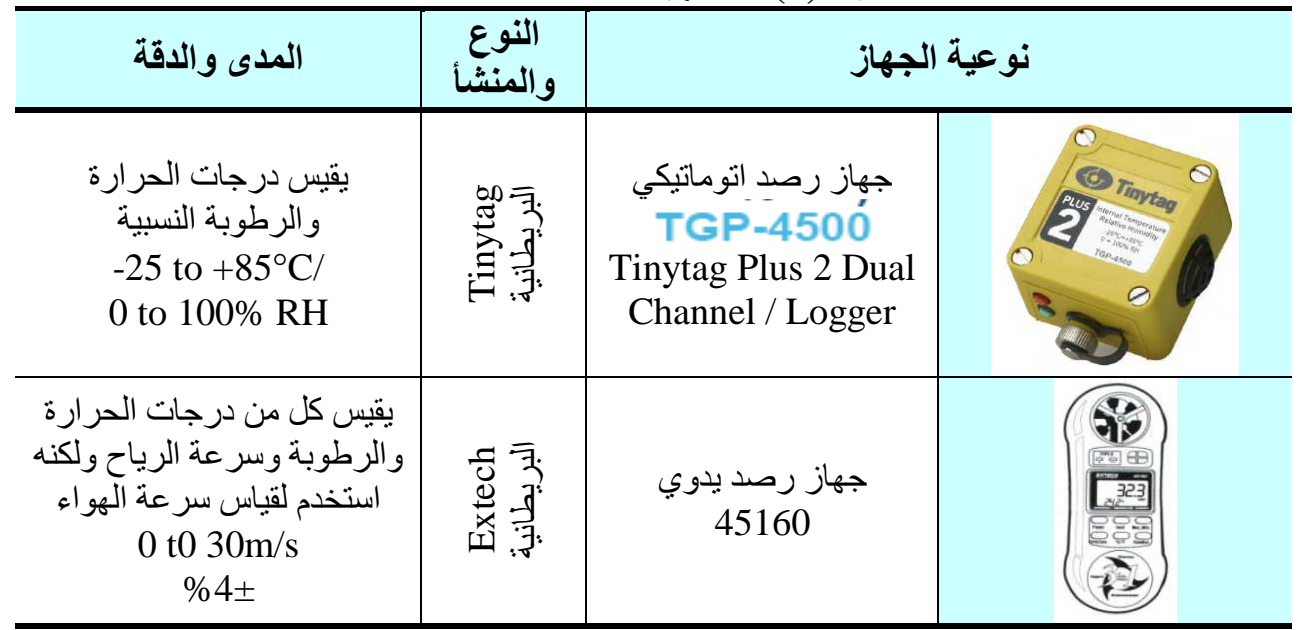

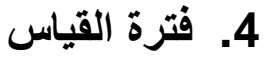

أجريت القياسات الميدانية بجميع الفراغات المختارة للقياس وذلك لكل من درجات الحر ارة و الرطوبة النسبية لمدة

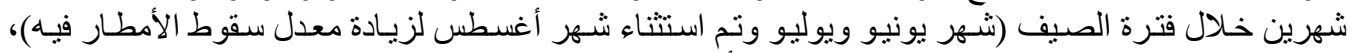

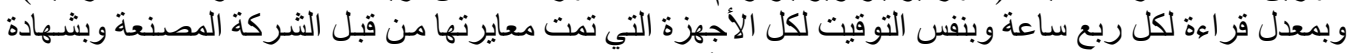

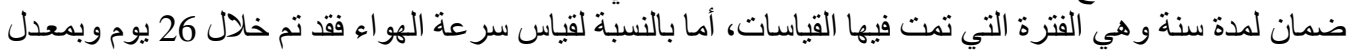

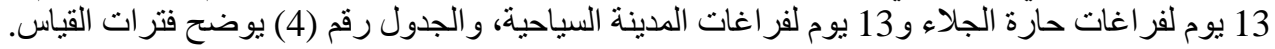

جدول (4): فترات القياس بفراغات الدراسة

\begin{tabular}{|c|c|c|c|}
\hline للاياسات اللقرة الزمنية & لارجترة الزمنية للقياسات المستمرة & عدد مواقع & المنطقة \\
\hline \multirow{2}{*}{$\begin{array}{c}2010 / 06 / 16 \\
- \\
2010 / 07 / 14\end{array}$} & \multirow{2}{*}{$\begin{array}{c}2010 / 05 / 31 \\
- \\
2010 / 07 / 30\end{array}$} & 4 & صنعاء القديمة \\
\hline & & 3 & 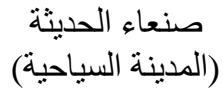 \\
\hline
\end{tabular}

\section{5. تحليل نتائج القياسات لفترة الصيف}

تم تحليل القياسات الميدانية بفر اغات الدر اسة في فترة الصيف، وذللك للتعرف على تأثير تلك الفر اغات على كل

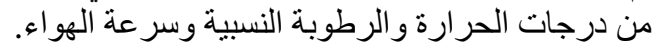

5. 1 تحليل قياسات درجات الحرارة:

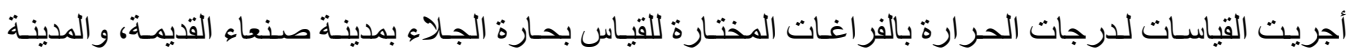

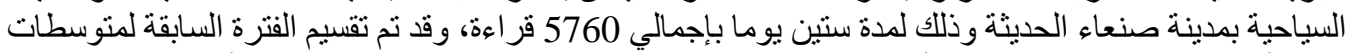

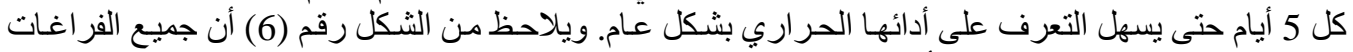

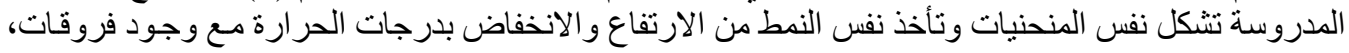




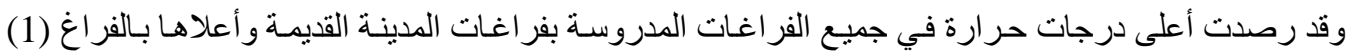

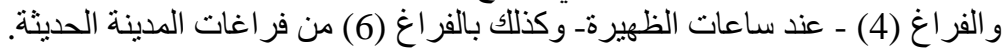

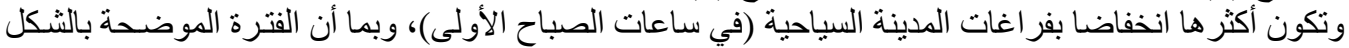

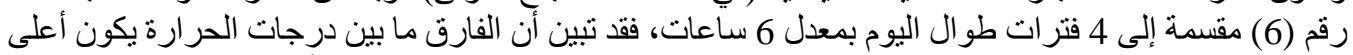

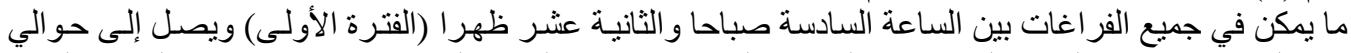

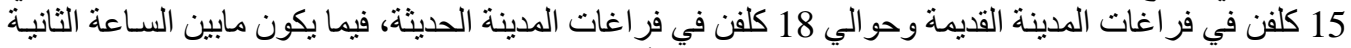

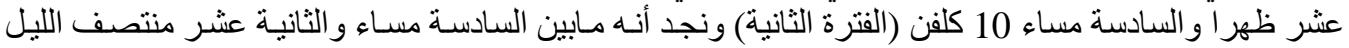

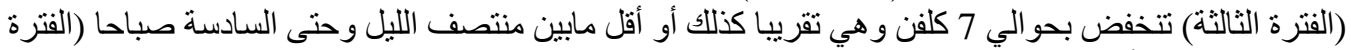

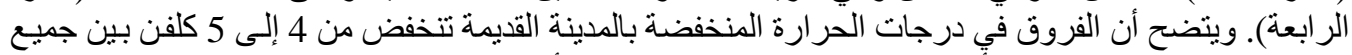

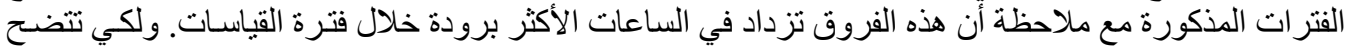

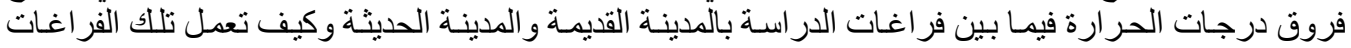

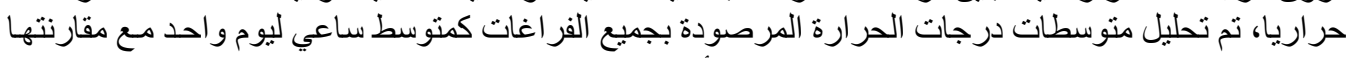

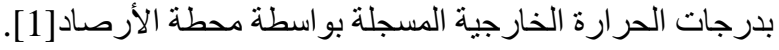
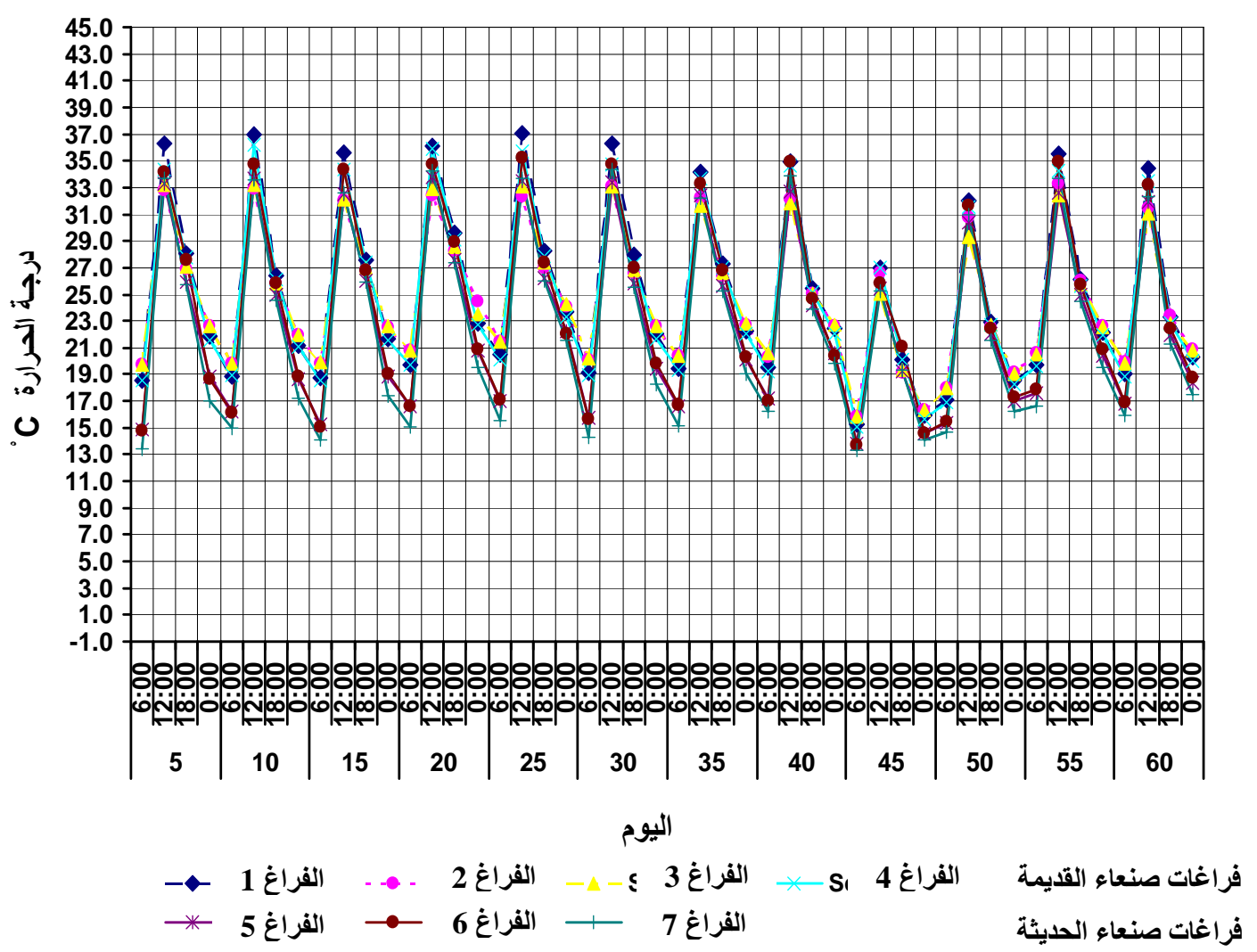

شكل(6): منحنيات درجات الحرارة بجميع الفر اغات العمر انية السكنية المختارة للار اسة ــ فترة الصيف.

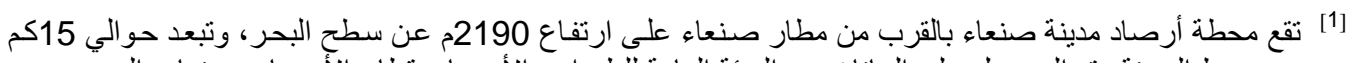

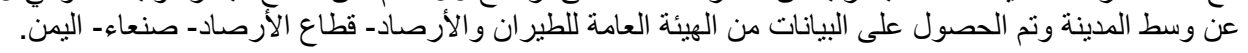




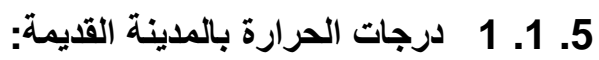

يتبين من الثكل رقم (7) أن أعلى درجات حر ارة سجلت بالفر اغ (4)، وقد رصدت باغ بالسـاعة الثانيـة ظهر ا وبفارق

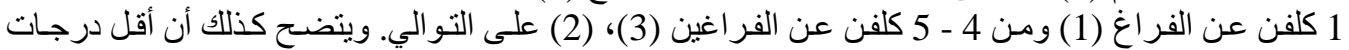

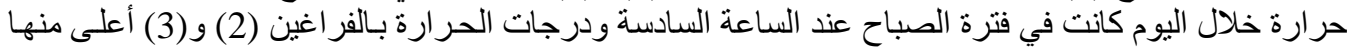

بالفر اغين (1) و (4) بفارق و احد كلفن تقريبا.

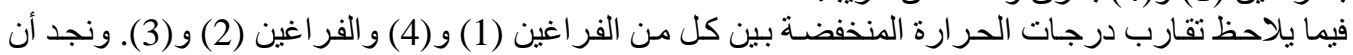

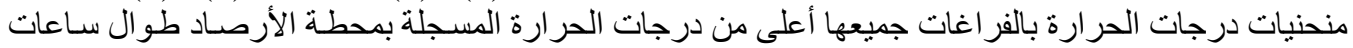

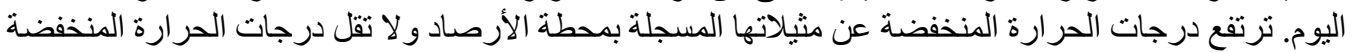
بفر اغات المدينة القديمة عن 19 19 س.
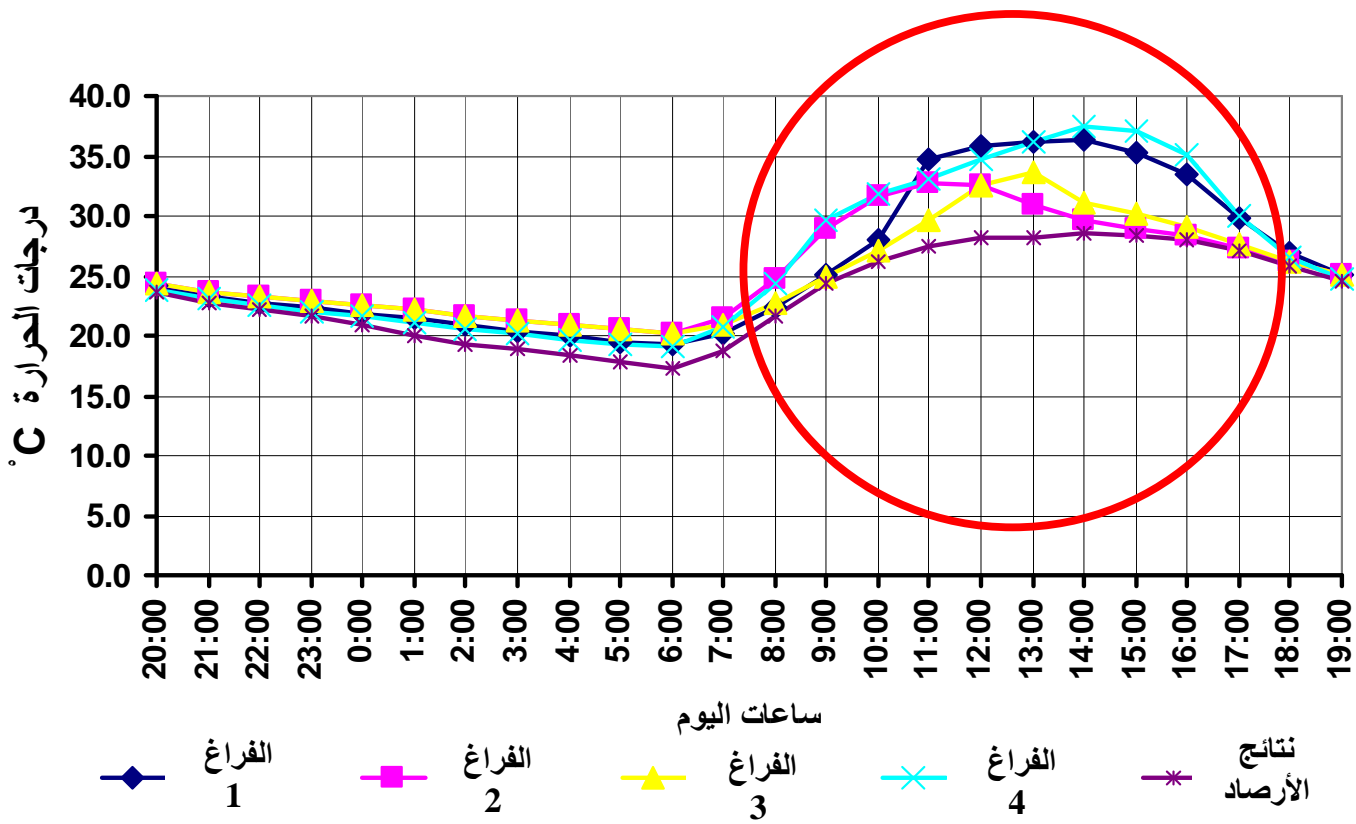

\begin{tabular}{|c|c|c|}
\hline \multicolumn{2}{|c|}{ أدنى درجات حرارة خلال اليوم } & رقم \\
\hline الوقت & لدرجات الحرارة & الفراغ \\
\hline السادسة صباحا & 19.2 س س & 1 \\
\hline السادسة صباحا & 20.2 & 2 \\
\hline السادسة صباحا & 20.2 س س & 3 \\
\hline السادسة صباحا & 19.1 س س & 4 \\
\hline السادسة صباحا & 17.2 & قالرياسات \\
\hline
\end{tabular}

\begin{tabular}{|c|c|c|}
\hline \multicolumn{2}{|c|}{ أعلى درجات حرارة خلال اليوم } & \multirow{2}{*}{ رقم الفراغ } \\
\hline الوقت & درجات الحرارة & \\
\hline الثانية ظهرا & 36.4 & 1 \\
\hline الحادية عشر ظهرا & س³2.7 & 2 \\
\hline الواحدة ظهرا & 33.7 & 3 \\
\hline الثانية ظهرا & 37.5 & 4 \\
\hline الثالثة ظهرا & 28.5 & قالِياسات \\
\hline
\end{tabular}

شكل(7): درجات الحرارة بالفر اغات العمر انية السكنية المختارة للقياس بحارة الجلاء خلال فترة الصيف.

\section{1. 2 1. 2 درجات الحرارة بالمدينة الحديثة:}

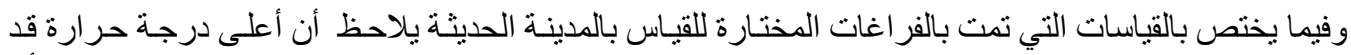

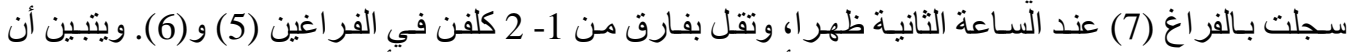

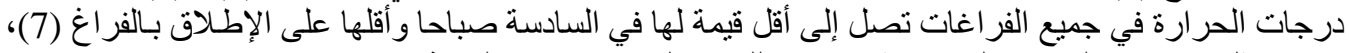
بينما تماثلت درجات الحرارة المنخفضة تقريبا وذلك في الفر اغين (5) واغل الفر اغ (6). 


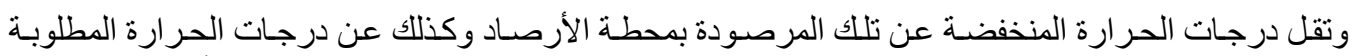

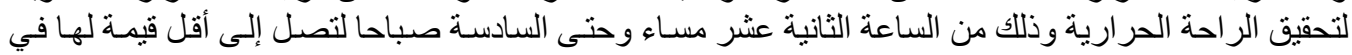

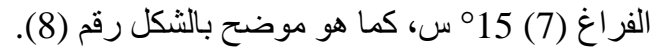

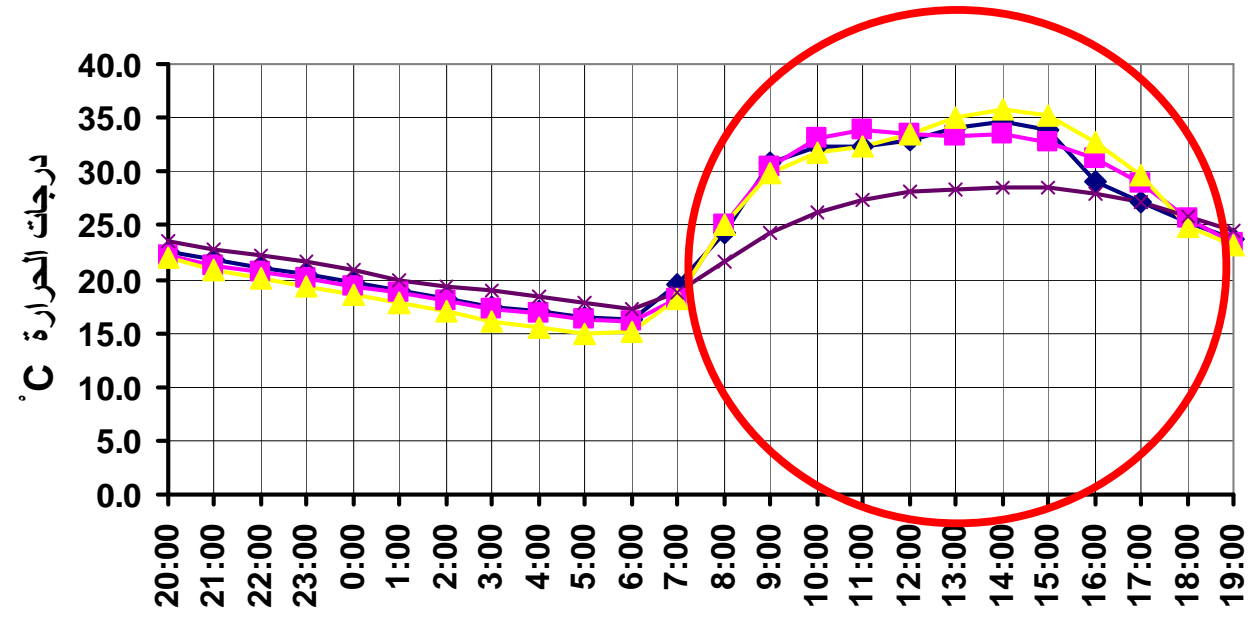

ساعاث اليوم

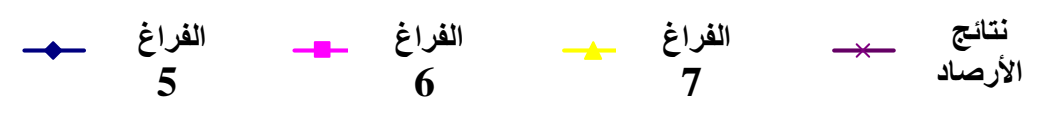

\begin{tabular}{|c|c|c|}
\hline \multicolumn{2}{|c|}{ أدنى درجات حرارة خلال اليوم } & \multirow{2}{*}{ رقم الفراغ } \\
\hline الوقت & لدرجات الحرارة & \\
\hline السادسة صباحا & 16.3 & 5 \\
\hline السادسة صباحا & 16.1 & 6 \\
\hline السادسة صباحا & 15.1 & 7 \\
\hline السادسة صباحا & 17.2 & قالياسات \\
\hline
\end{tabular}

\begin{tabular}{|c|c|c|}
\hline \multicolumn{2}{|c|}{ أعلى درجات حرارة خلال اليوم } & \multirow{2}{*}{ 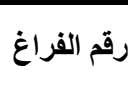 } \\
\hline الوقت & درجات الحرارة & \\
\hline الثانية ظهرا & 34.7 س س & 5 \\
\hline الثانية ظهرا & 33.5 س س & 6 \\
\hline الثانية ظهرا & 35.8 س س & 7 \\
\hline الثانية ظهرا & 28.5 & قالِّاسات \\
\hline
\end{tabular}

شكل(8): درجات الحرارة بالفر اغات العمر انية السكنية المختارة للقياس بالمدينة السياحية خلال فترة الصيف.

5 2 2 تحليل قياسات الرطوبة النسبية:

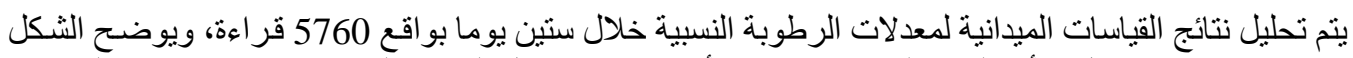

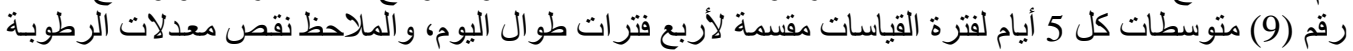

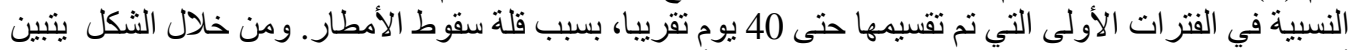

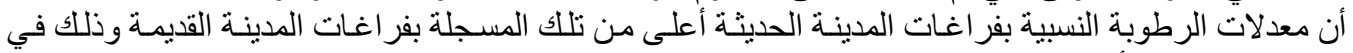

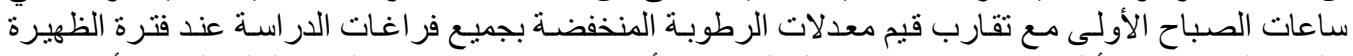

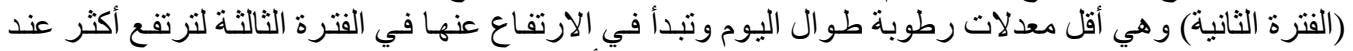

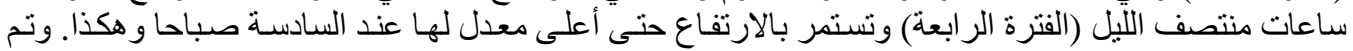

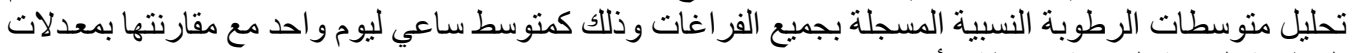
الرطوبة النسبية المقاسة بمحطة الرطة الربة الرصاد. 
م.سمبرة صالح حسين الثاوش , أ بـ .مراد عبد القادر عبد المحسن , أ بـ عبل المنطلب محد علي

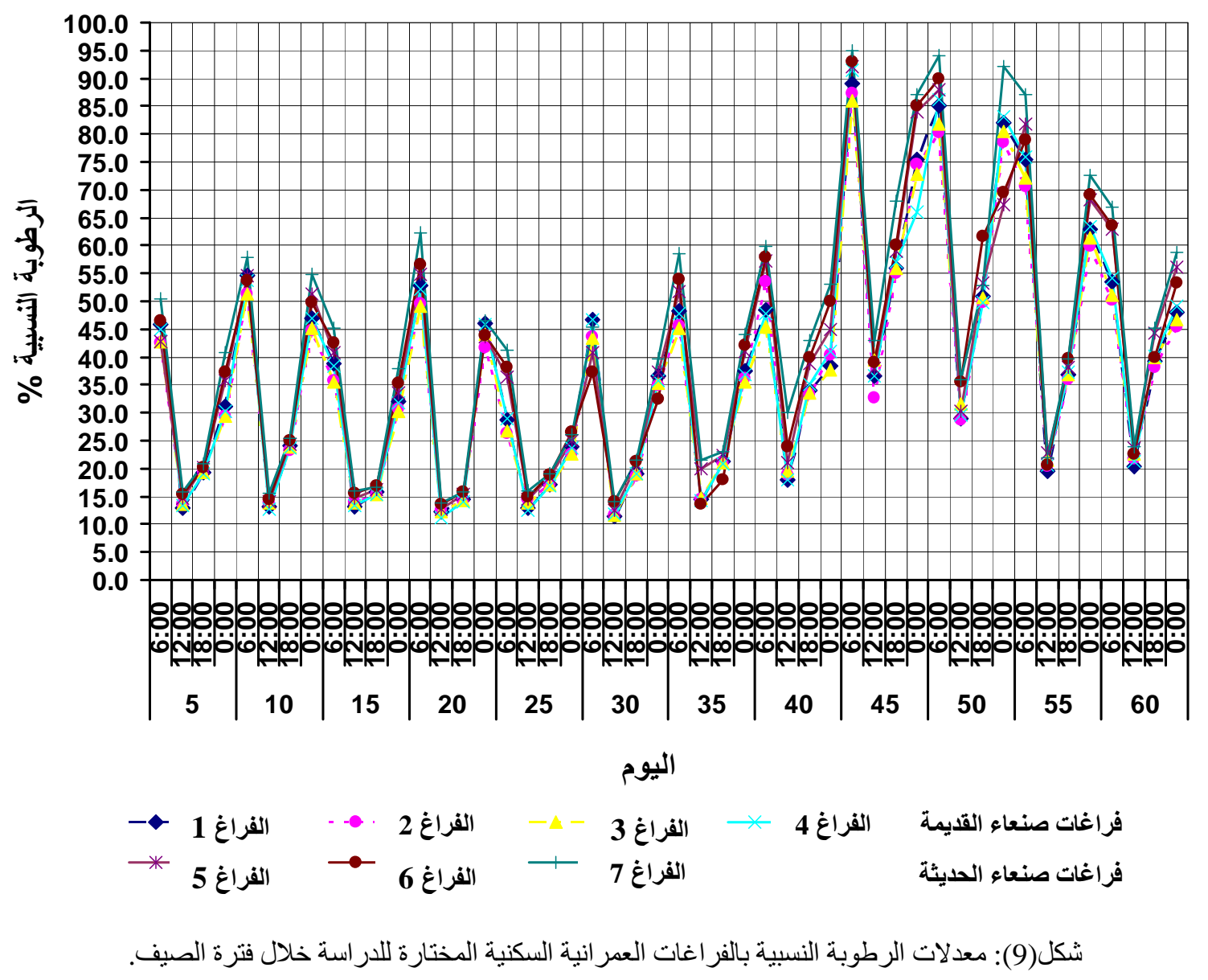

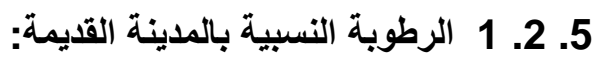

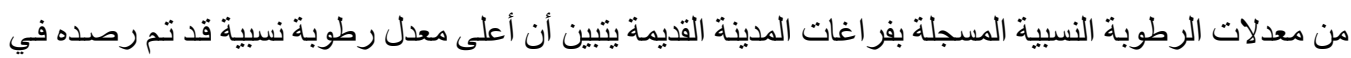

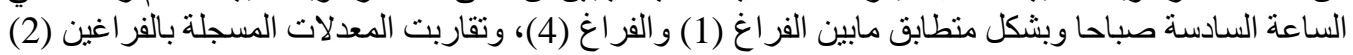

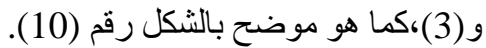

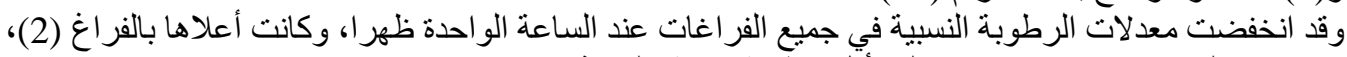

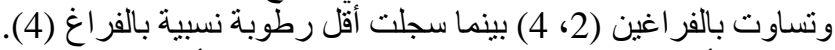

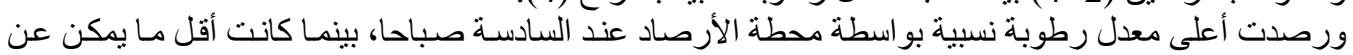

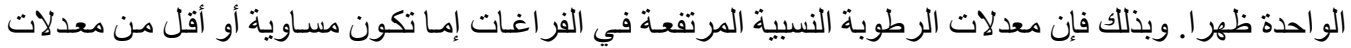

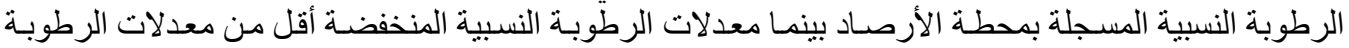

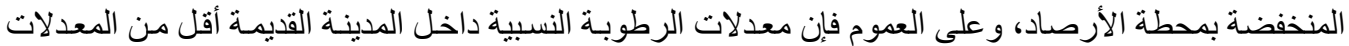

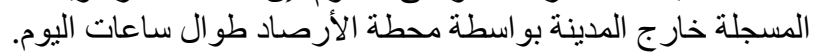




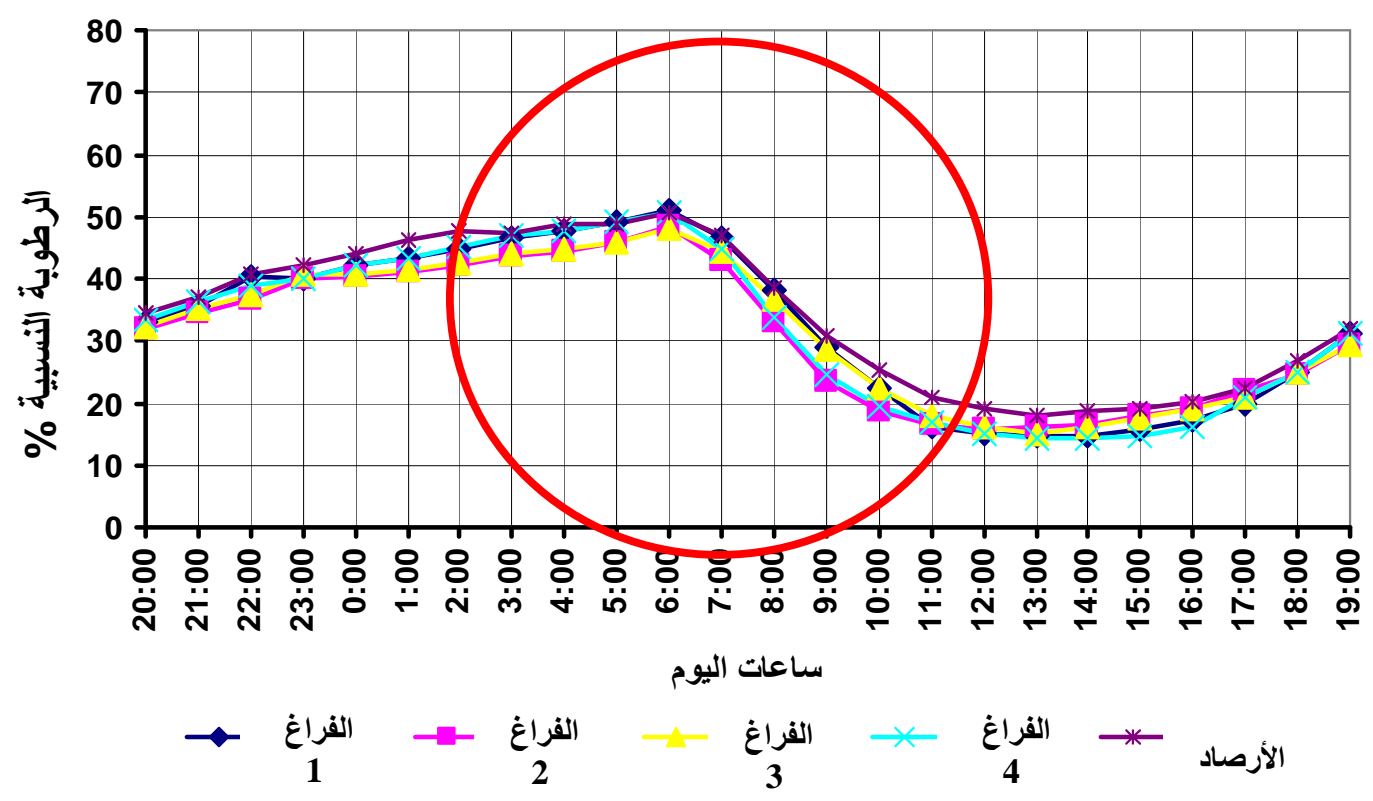

\begin{tabular}{|c|c|c|}
\hline \multicolumn{2}{|c|}{ أدنى رطوبة نسبية خلال اليوم } & \multirow{2}{*}{ رقم الفراغ } \\
\hline الوقت & الرطوبة النسبية & \\
\hline الواحدة ظهرا & $\% 15$ & 1 \\
\hline الواحدة ظهرا & $\% 16$ & 2 \\
\hline الواحدة ظهرا & $\% 15$ & 3 \\
\hline الواحدة ظهرا & $\% 14$ & 4 \\
\hline الواحدة ظهرا & $\% 18$ & قالأياساد \\
\hline
\end{tabular}

\begin{tabular}{|c|c|c|}
\hline \multicolumn{2}{|c|}{ أعلى رطوبة نسبية خلال اليوم } & \multirow{2}{*}{ رقم الفراغ } \\
\hline الوقت & الرطوبة النسبية & \\
\hline السادسة صباحا & $\% 51$ & 1 \\
\hline السادسة صباحا & $\% 49$ & 2 \\
\hline السادسة صباحا & $\% 48$ & 3 \\
\hline السادسة صباحا & $\% 51$ & 4 \\
\hline السادسة صباحا & $\% 51$ & قأِياسات \\
\hline
\end{tabular}

شكل(10): الرطوبة النسبية بالفر اغات العمر انية السكنية المختارة للقياس بمدينة صنعاء القديمة خلال فترة الصيف.

5. 2.2 2 الرطوبة النسبية بالمدينة الحديثة:

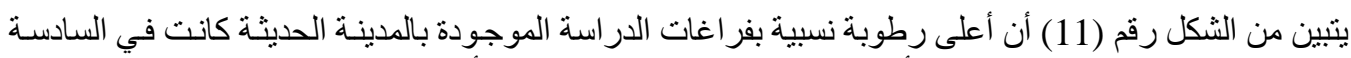

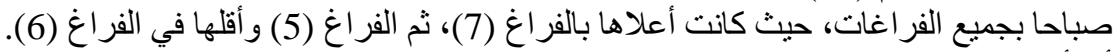

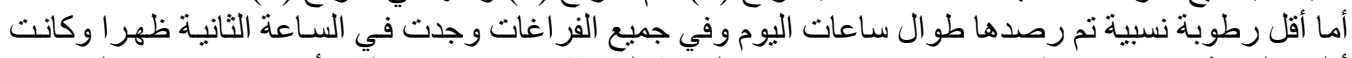

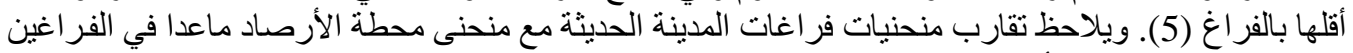

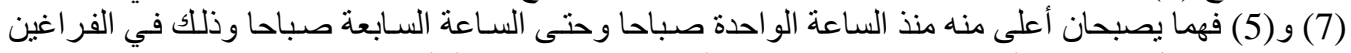
(5) و (7). و (5قل منحنيات الفر اغات جميعها عنه من الثامنة صباحا وحتى الثالثة ظهر ا. 


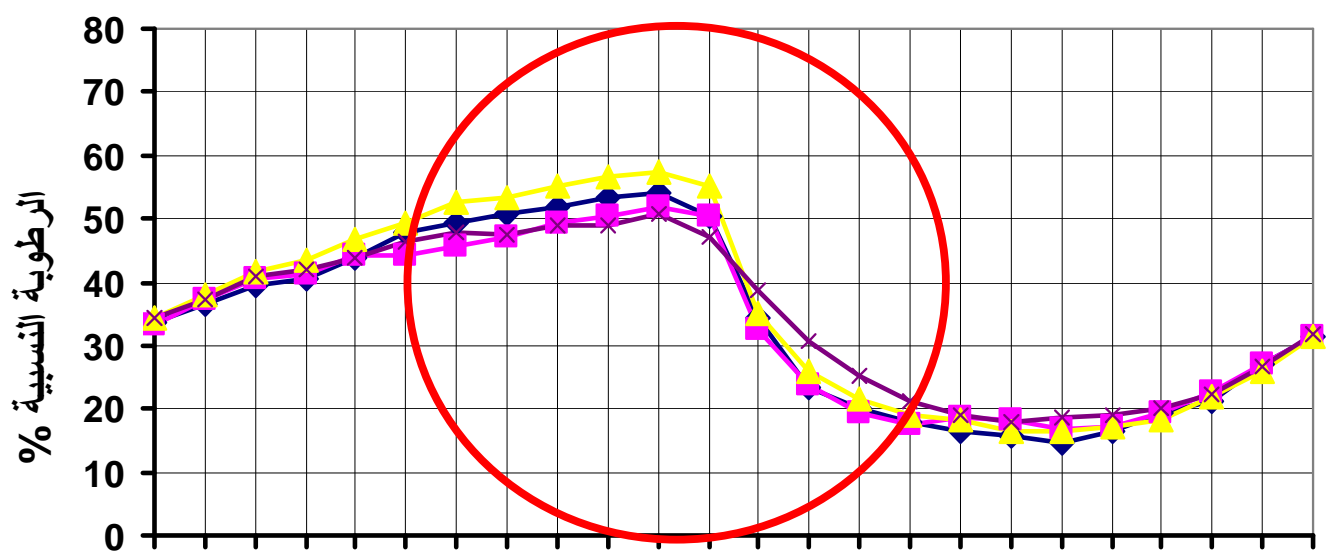

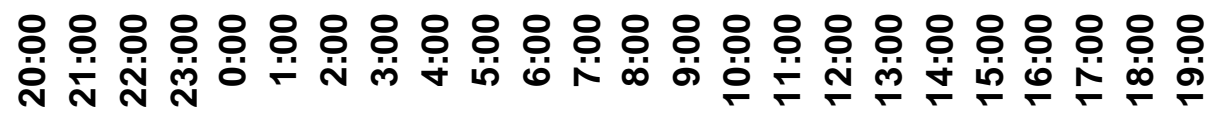

ساعات اليوم

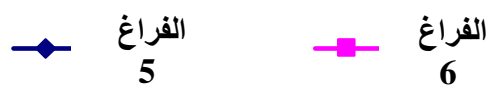

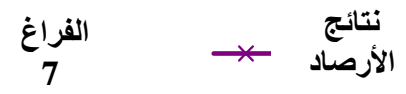

\begin{tabular}{|c|c|c|}
\hline \multicolumn{2}{|c|}{ أدنى رطوبة نسبية خلال اليوم } & رقم \\
\hline الوقت & الرطوبة النسبية & 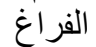 \\
\hline الثانية ظهرا & $\% 15$ & 5 \\
\hline الثانية ظهرا & $\% 17$ & 6 \\
\hline الثانية ظهرا & $\% 16$ & 7 \\
\hline الواحدة ظهرا & $\% 18$ & قالياسات \\
\hline
\end{tabular}

\begin{tabular}{|c|c|c|}
\hline \multicolumn{2}{|c|}{ أعلى رطوبة نسبية خلال اليوم } & رقم \\
\hline الوقت & الرطوبة النسبية & الفر اغ \\
\hline السادسة صباحا & $\% 53$ & 5 \\
\hline السادسة صباحا & $\% 50$ & 6 \\
\hline السادسة صباحا & $\% 57$ & 7 \\
\hline السادسة صباحا & $\% 51$ & قأياسات \\
\hline
\end{tabular}

شكل (11): الرطوبة النسبية بالفر اغات العمر انية السكنية المختارة للقياس بمدينة صنعاء الحديثة خلال فترة الصيف.

5. 3 ت تليل قياسات سرعة الهواء:

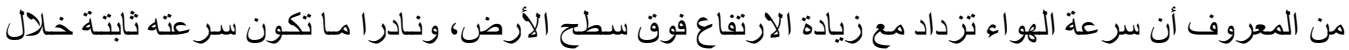

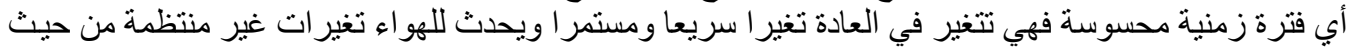

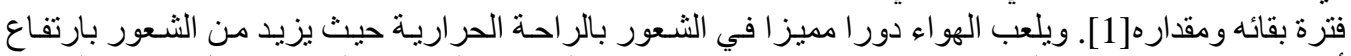

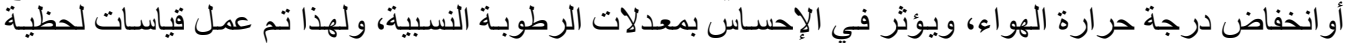

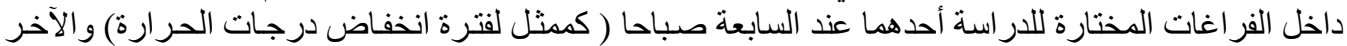

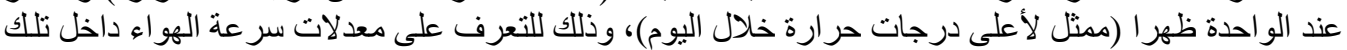

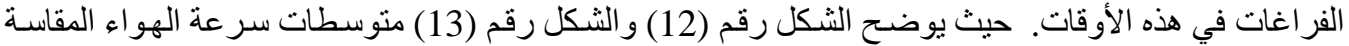

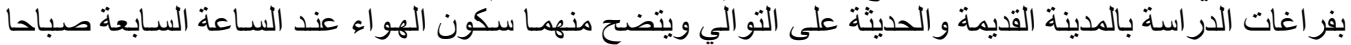

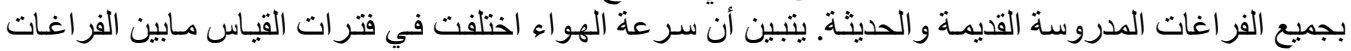

[1] ب.ج. ريتالكلاك،؛" موجز محاضر ات لتدريب العاملين في الأرصاد الجوية من الفئة الر ابعة"، سكرتارية المنظمة العالمية

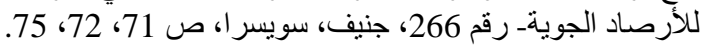




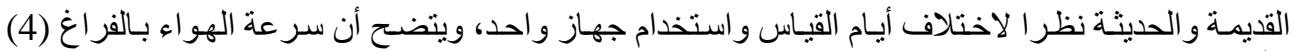

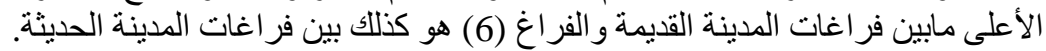

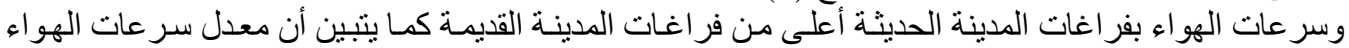

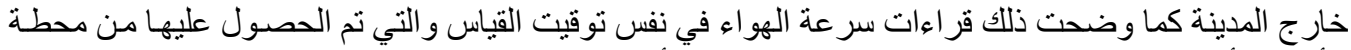

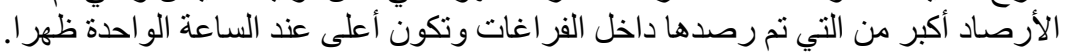

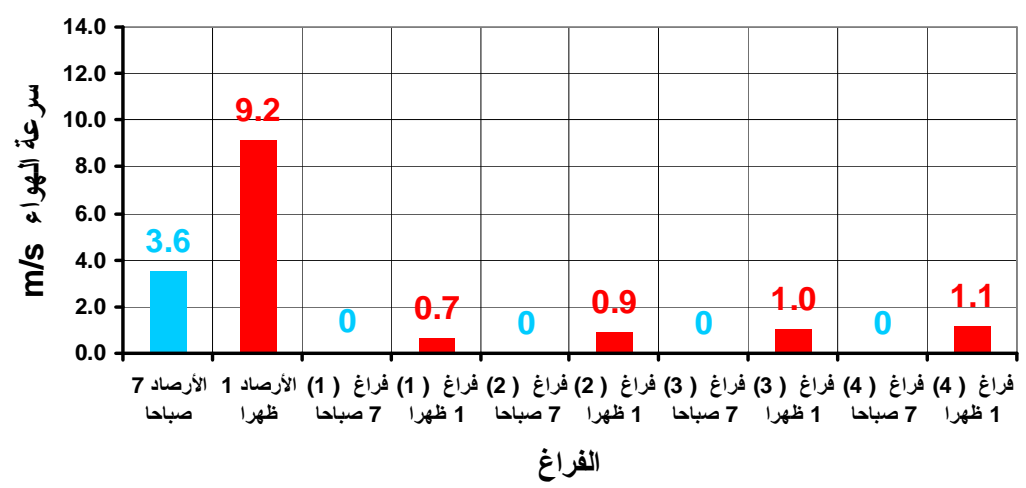

شكل(12): متوسطات سر عة الرياح المقاسة بفر اغات حارة الجلاءـ المدينة القديمة بفترة الصبف

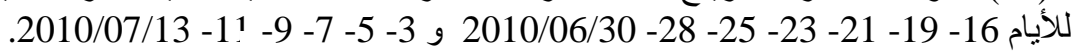

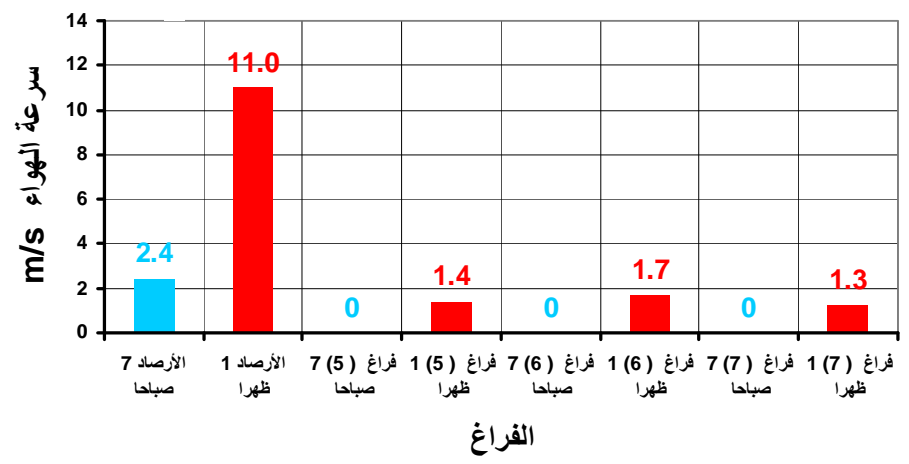

شكل(13): متوسطات سر عة الرياح المقاسة بفر اغات المدينة السياحيةـ المدينة الحديثة بفترة الصيف

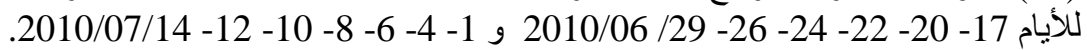

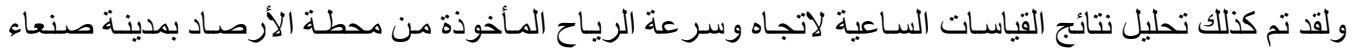

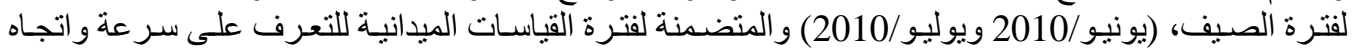

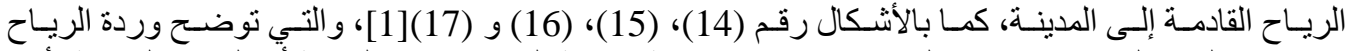

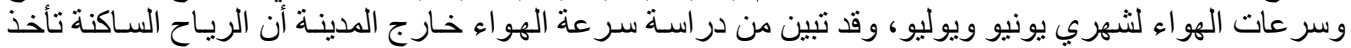

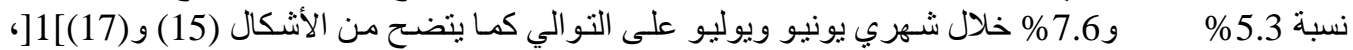

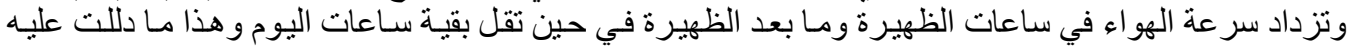

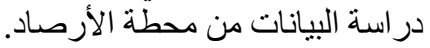

Lakes Environment software 1999-2008 version 5.9 من عمل الباحثة بو اسطة برنامج ]1] 


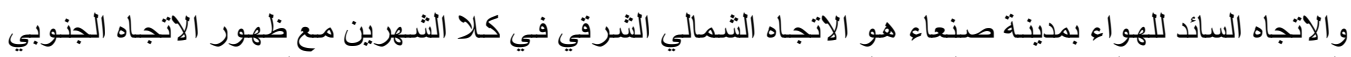

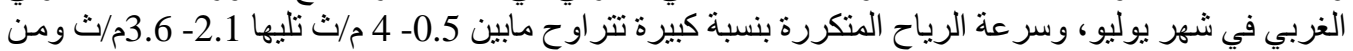

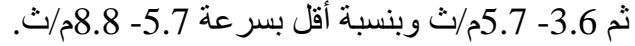
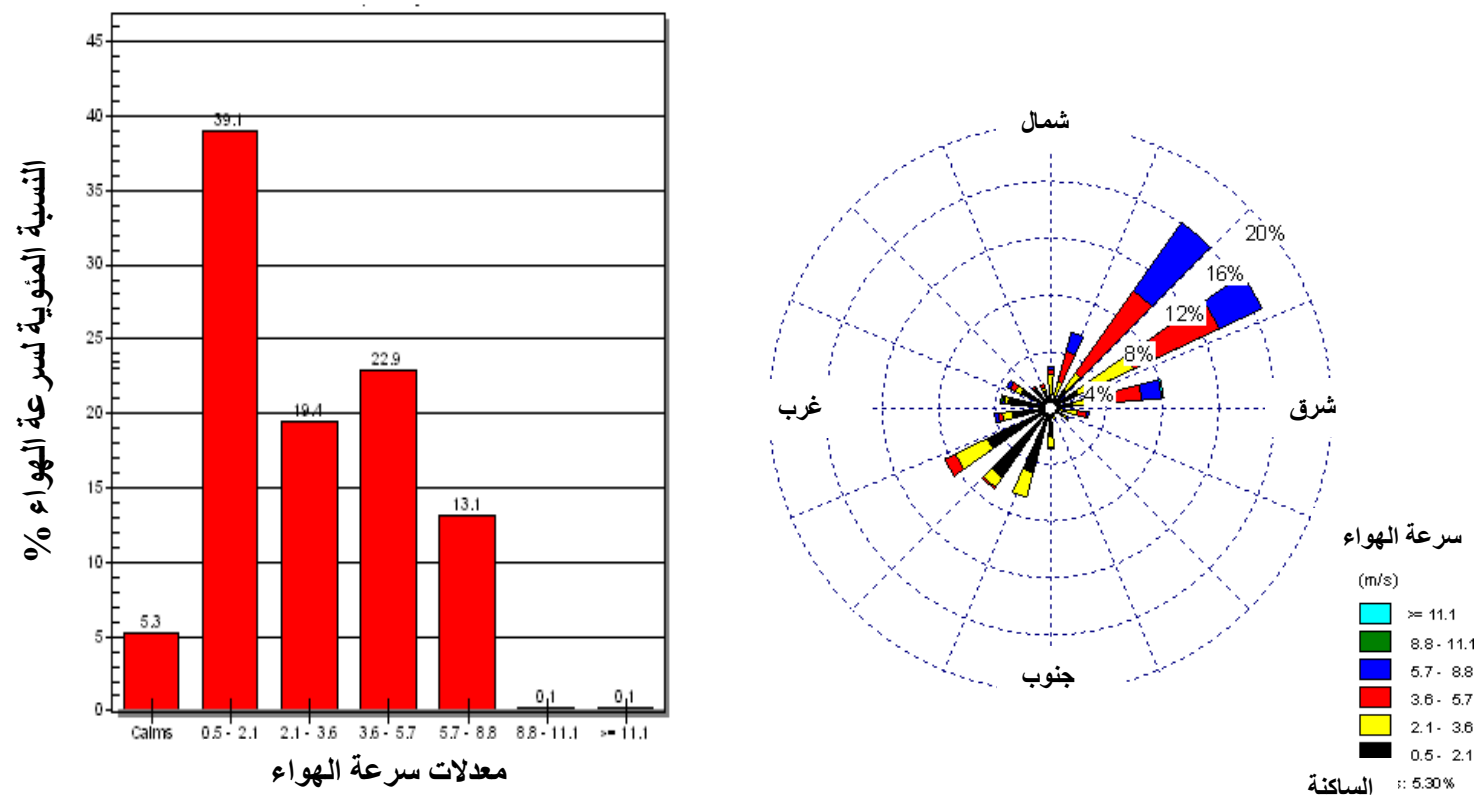

شكل (15): سر عة الرياح لشهر يونيو - 2010

شكل (14): وردة الرياح لشهر يونيو - 2010.
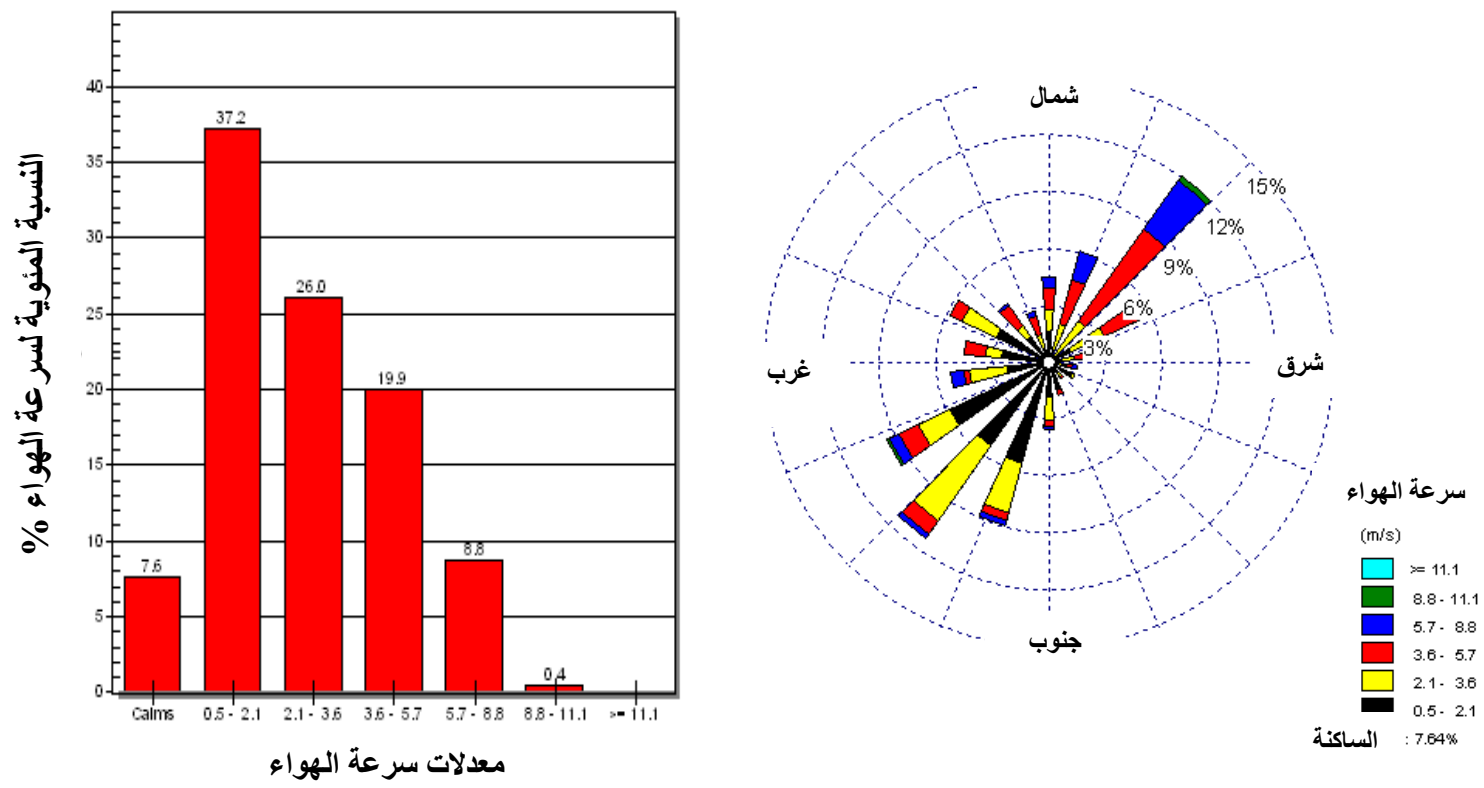

شكل(17): سرعة الرياح لشهر يوليو - معلاء سوراء 2010

شكل(16): وردة الرياح لشهر يوليو - 2010 


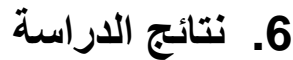

ركزت الدر اسة الحالية على فصل الصيف باعتباره من الفتر ات المهمة في مناخ مدينة صنعاء ويتضح من الدراسة السابقة ما يلي: الارية الئ

ـ ـ من المعروف أن درجات الحر ارة في فصل الصيف تكون أعلى من غير ها في جميع فصول العام. ولكن مدينة

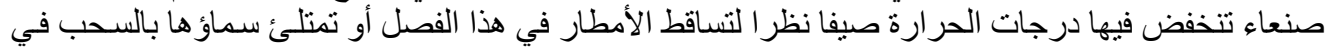

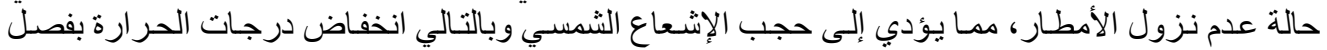

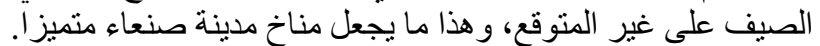

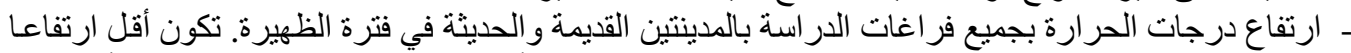

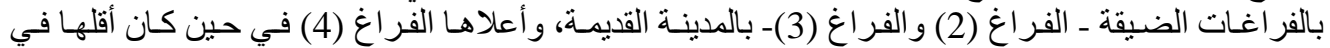

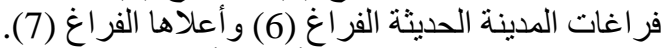

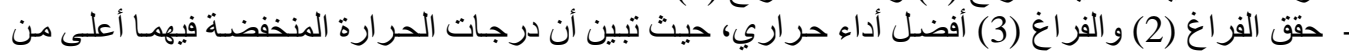

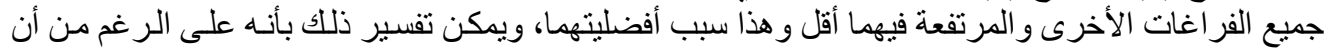

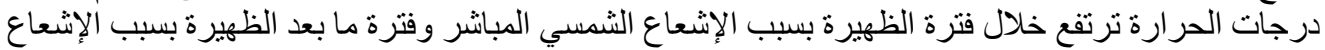

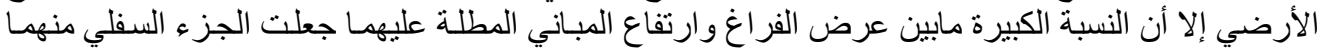

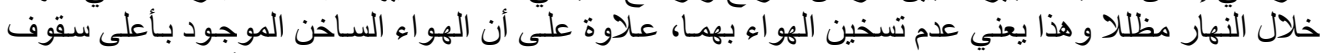

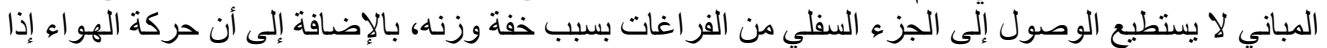

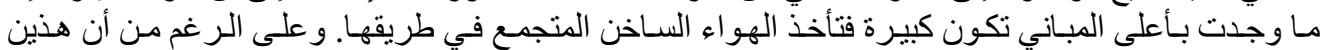

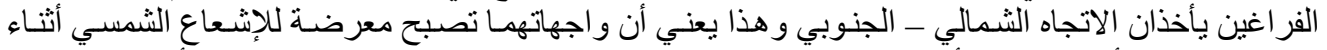

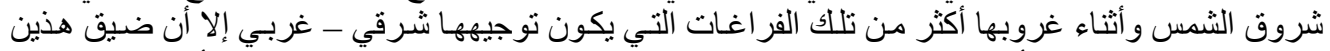

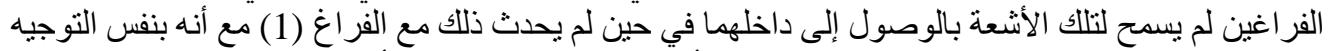

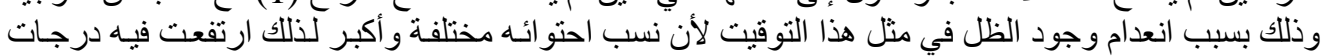

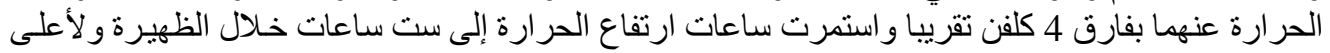

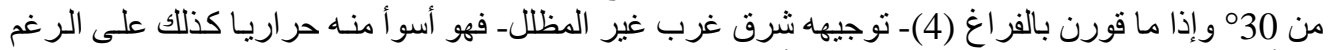

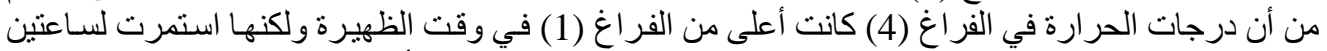

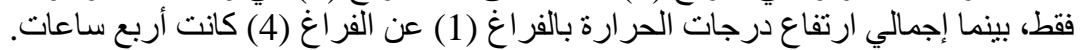

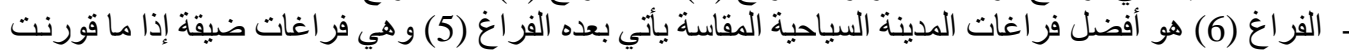

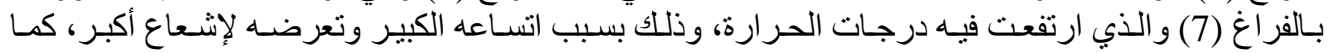

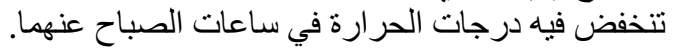

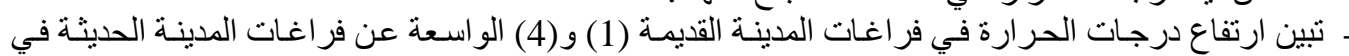

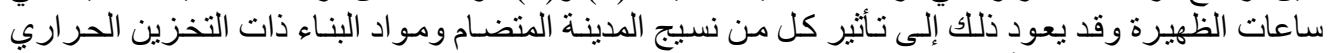
الكبير (الحجر و الطوب الظوة الأحمر ).

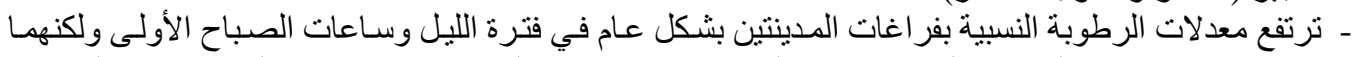

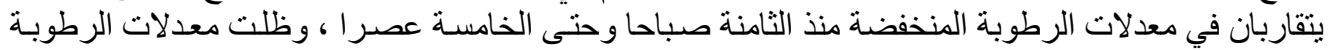

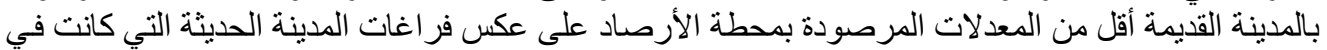

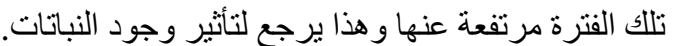

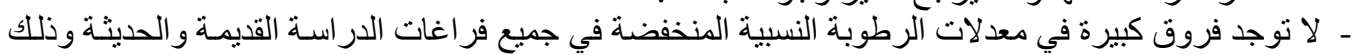

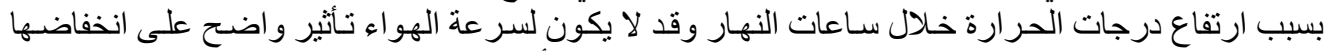

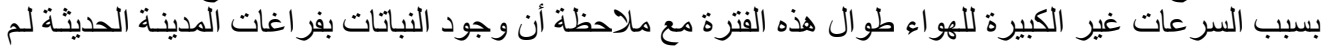

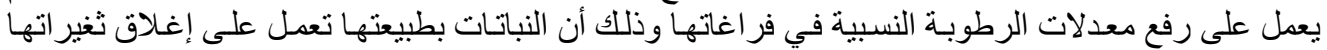

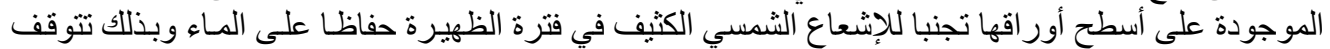

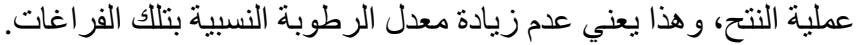

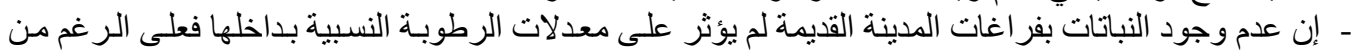

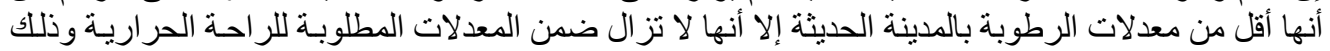

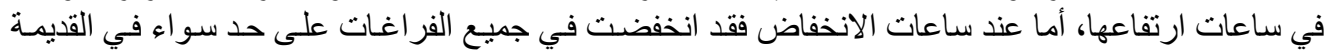


- سر عة الهو اء بفر اغات المدينة السياحية بفترة الصيف أكبر من تلك المسجلة بفر اغات المدينة القديمة في الظهيرة

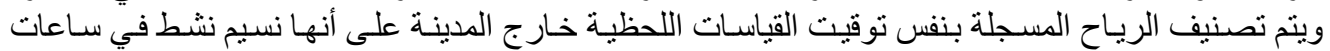

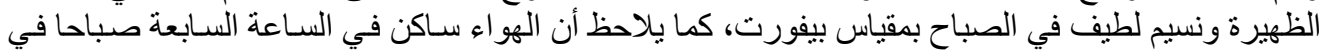

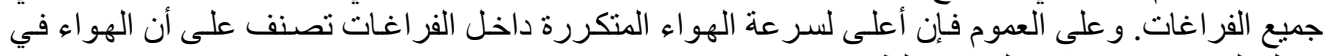

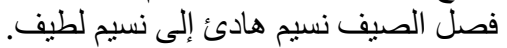

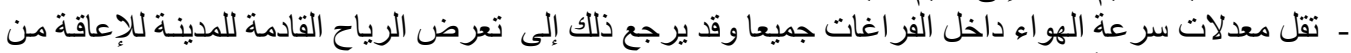

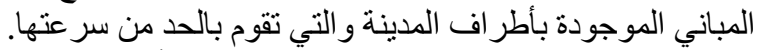

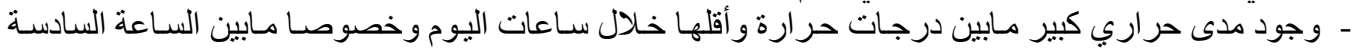

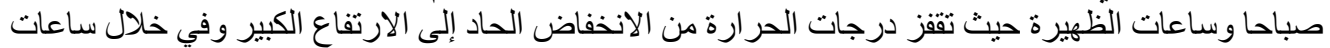

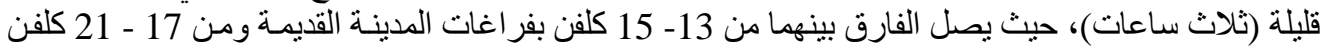
بفر اغات المدينة الحديثة.

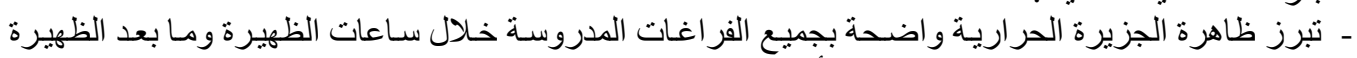

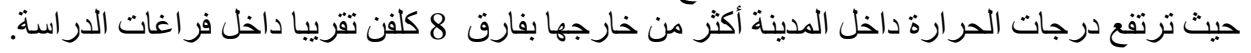

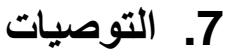

نتيجة لما سبق توصلت الدر اسة لمجمو عة من التوصيات التي من يمكن أخذها بعين الاعتبار، وفيما يلي عرض لأ أهمها:

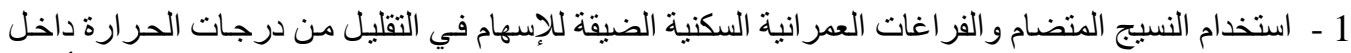

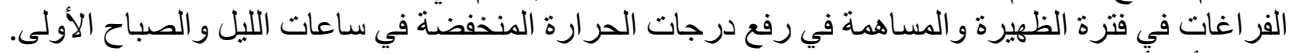

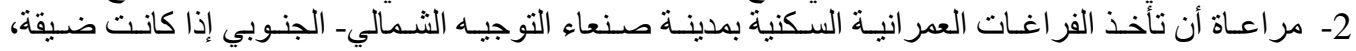

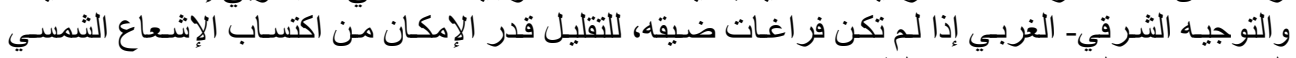

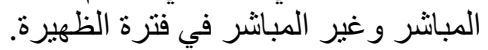

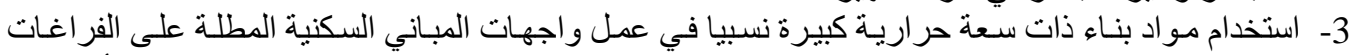

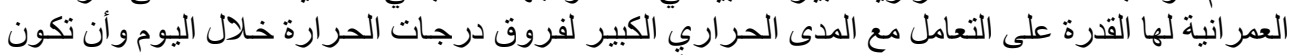

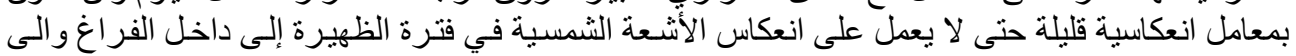

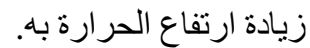

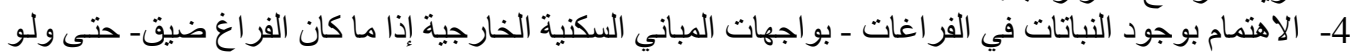

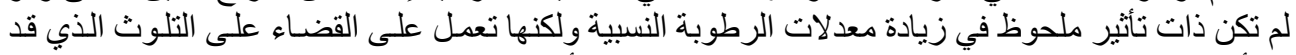

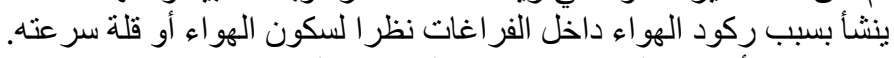

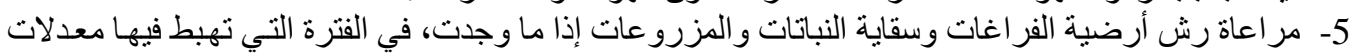

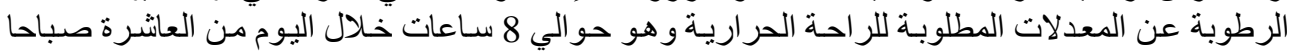

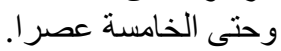

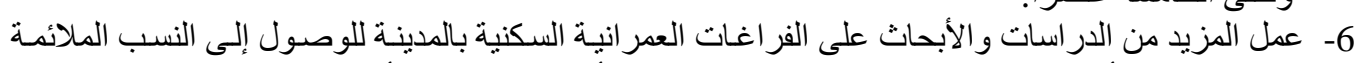

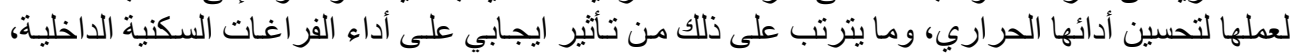

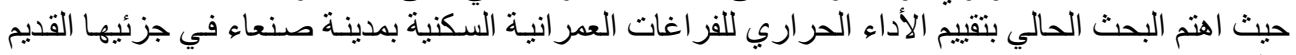
و الحديث. 


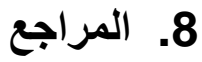

[1] [ الهيئة العامة للطير ان و الأرصاد، قطاع الأرصاد، صنعاء، اليمن، أغسطس 2010.

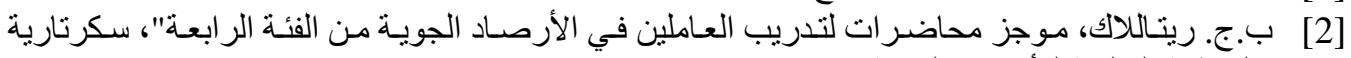

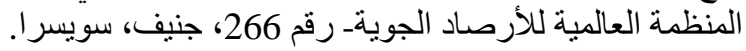

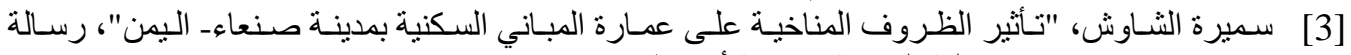

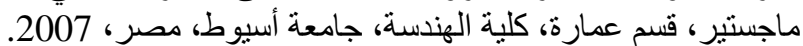

[4] شركة تيم الدولية للهندسة والتدريب، مهندسون استثاريون، لبنـان:" الدر اسـة الثـاملة لتنظيم حركة المرور

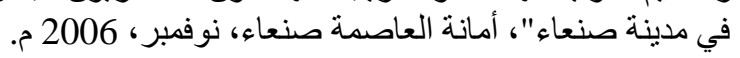

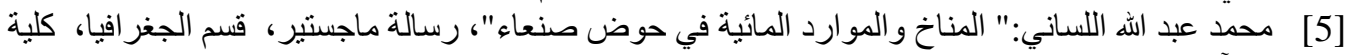

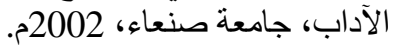

[6] مركز التدريب المعماري، الهيئة العامة للمحافظة على المدن التاريخية، صنعاء، اليمن، تحديث 2008.

[7] Lakes Environment software 1999-2008 version 5.9.

[8] http://www.marefa.org/index.php 2010/5/23

[9] http://travel.m3com.com.sa2010/5/23

${ }^{] 1} 0$ [http://www.google Earth 2010/10/12 

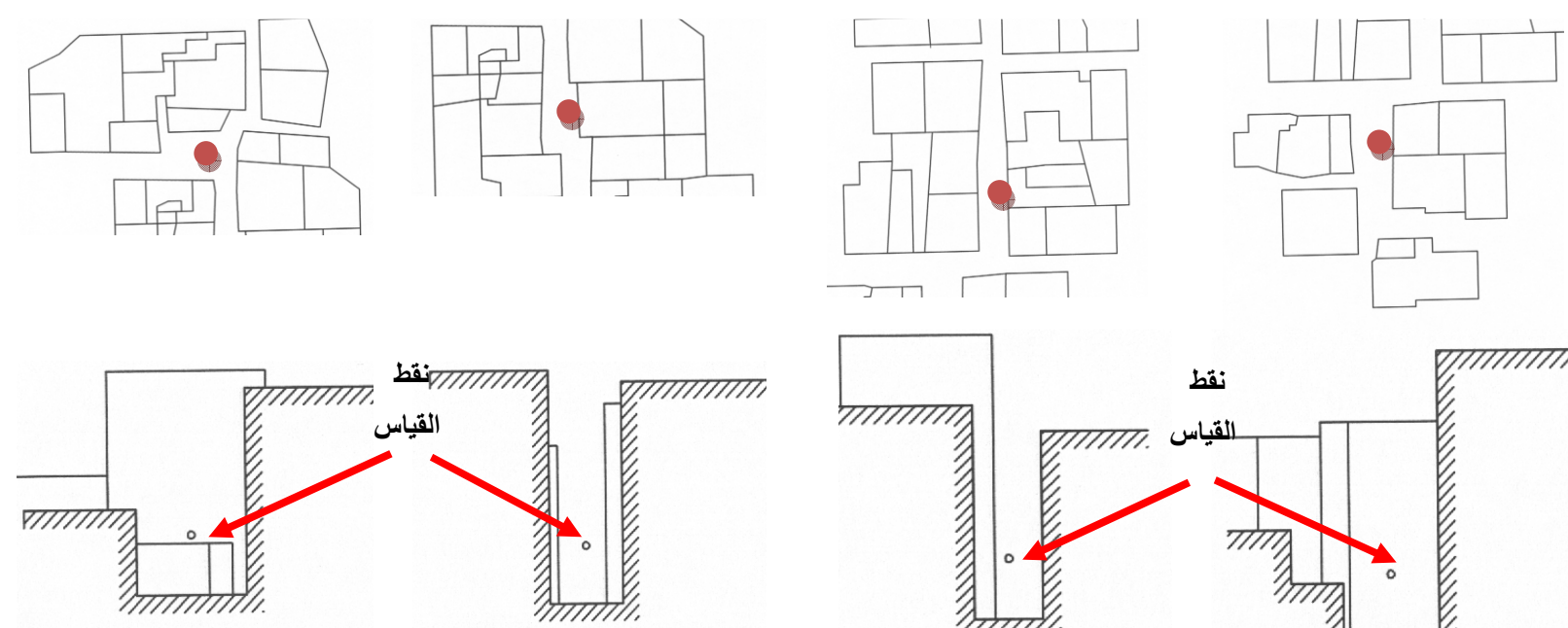

$5 \mathrm{~m}$

فراغ

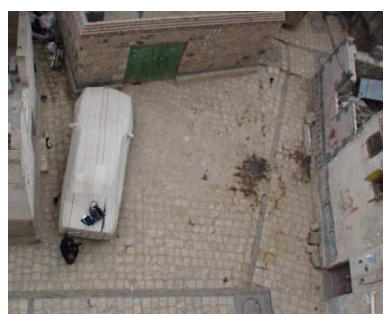

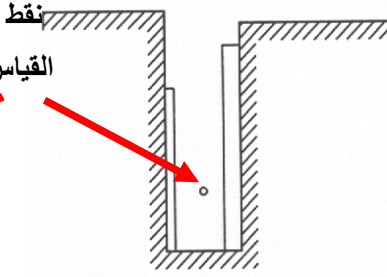

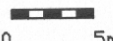

فراغ

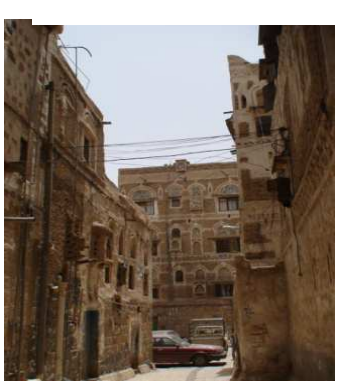

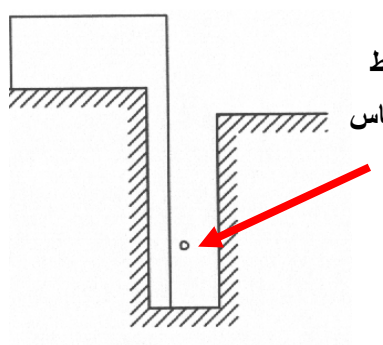

$5 \mathrm{~m}$

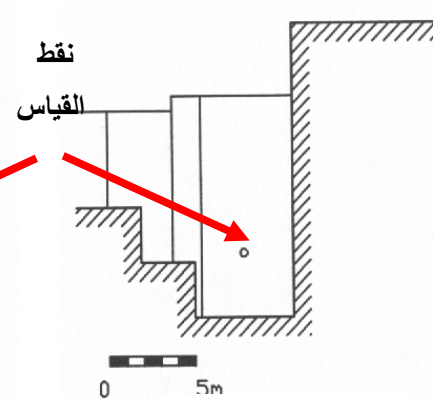

فراغ (2)

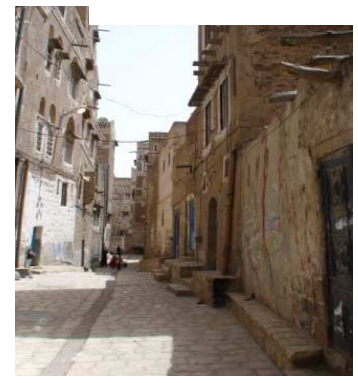

فراغ (1)

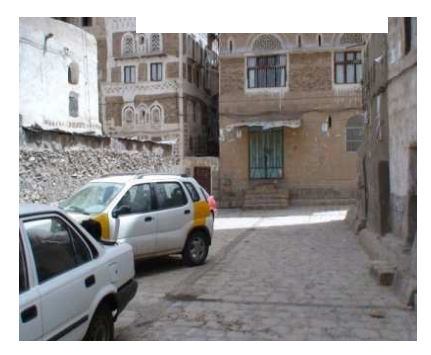

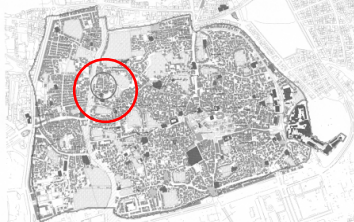

موقع منطقة القياسات (حارة الجلاء) بالنسبة للمدينة القديمة
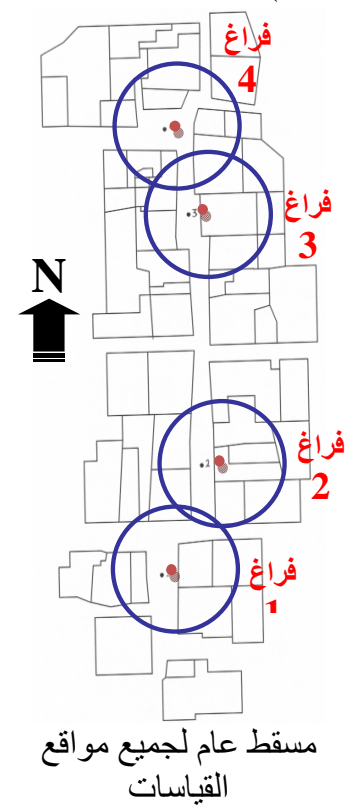

شكل (4): مواقع القياسات بحارة الجلاء ـ المدينة القديمة. 

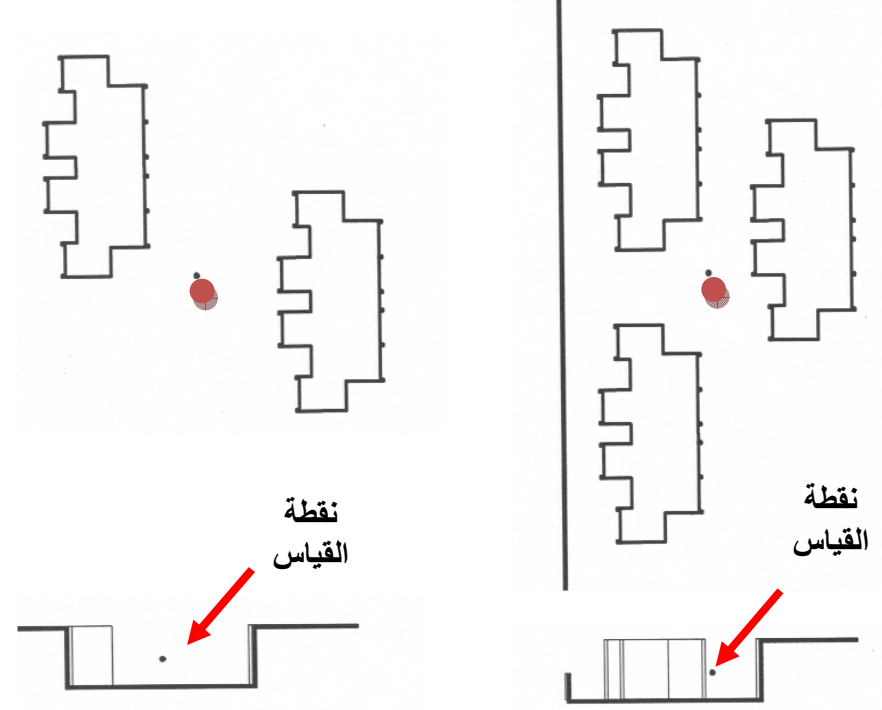

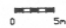

فراغ (6)

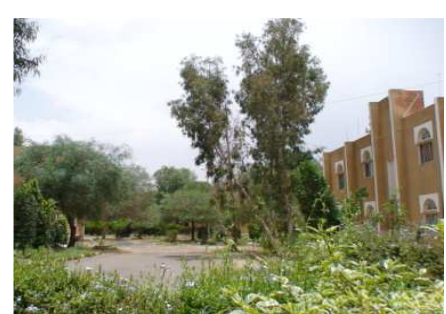

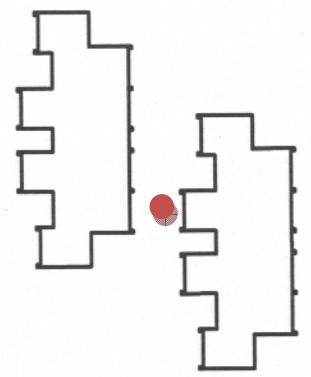

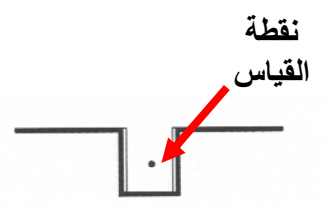

$x_{\text {sn }}$
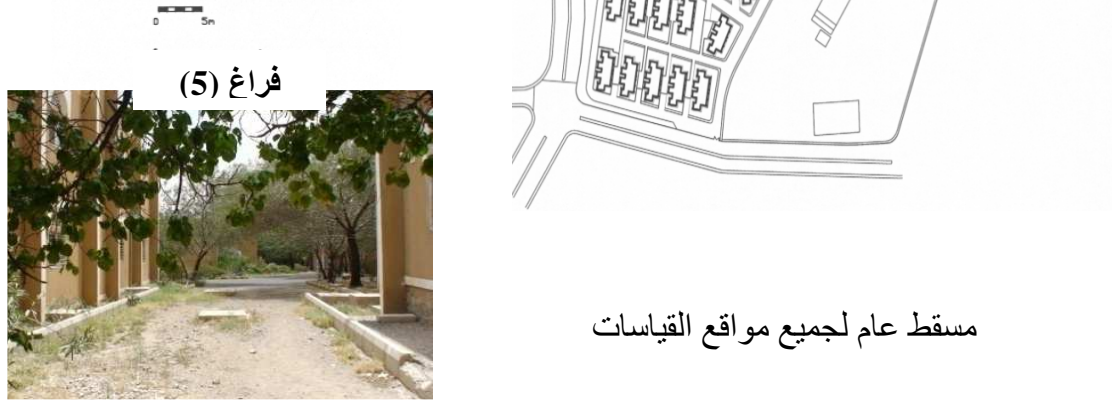

مسقط عام لجميع مواقع القياسات

شكل (5): مو اقع القياسات بالمدينة الحديثة (المدينة السياحيةـ شيراتون). 